Universidad de Lima

Facultad de Ciencias Empresariales y Económicas

Carrera de Contabilidad

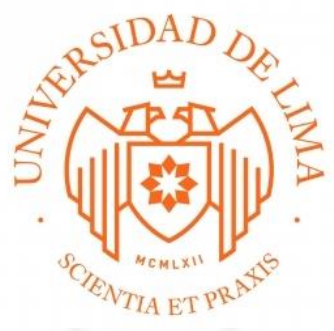

ANÁLISIS Y PROYECCIÓN DE LOS ESTADOS FINANCIEROS MEDIANTE LA APLICACIÓN DE RATIOS FINANCIEROS

PARA LA TOMA DE DECISIONES DE MANUFACTURA DE METALES Y ALUMINIO RECORD S.A. 2018-2022

Trabajo de suficiencia profesional para optar el Título Profesional de Contador Público

Carolina Llaxa Salazar

Código 20100620

Asesor

Carlos Paredes Reátegui

Lima - Perú

Octubre de 2018 


\section{ANÁLISIS Y PROYECCIÓN DE LOS ESTADOS FINANCIEROS MEDIANTE LA APLICACIÓN DE RATIOS FINANCIEROS \\ PARA LA TOMA DE DECISIONES DE MANUFACTURA DE METALES Y ALUMINIO RECORD S.A. 2018-2022}




\section{DEDICATORIA}

Este presente trabajo está dedicado en primer lugar a Dios por haberme permitido llegar hasta este punto. A mis padres por haberme apoyado en todo momento y por la motivación constante. A mi asesor por su gran apoyo y paciencia para poder culminar este trabajo. A los profesores de la Universidad de Lima por transmitirnos todos sus conocimientos y años de experiencia en esta carrera. 


\section{TABLA DE CONTENIDO}

\section{INTRODUCCIÓN}

CAPÍTULO I. ANTECEDENTES DE MANUFACTURA DE METALES Y

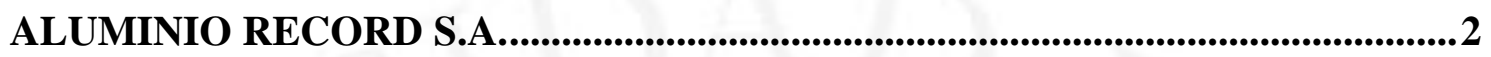

1.1. Historia, identificación y actividad económica de Manufactura de Metales y

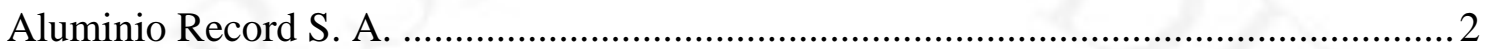

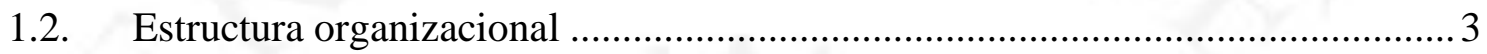

1.3. Aspectos organizativos y funcionales....................................................... 4

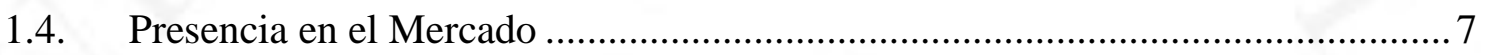

1.4.1 Participación de Mercado de Manufactura de Metales y Aluminio Recor1d S.A7

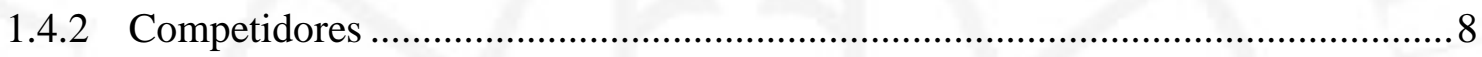

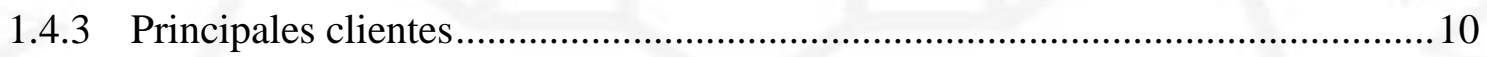

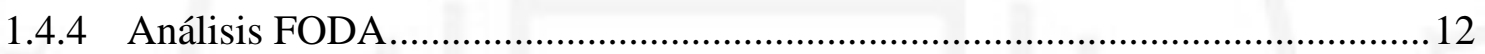

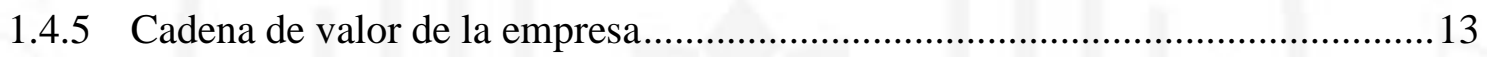

1.4.6 Evaluación de la posición estratégica de la empresa ........................................ 14

CAPÍTULO II. DESCRIPCIÓN Y OBJETIVOS DEL TRABAJO DE

SUFICIENCIA PROFESIONAL .................................................................................. 16

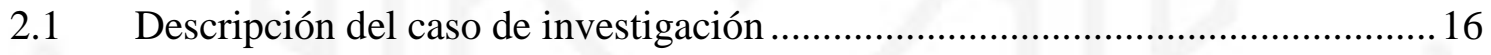

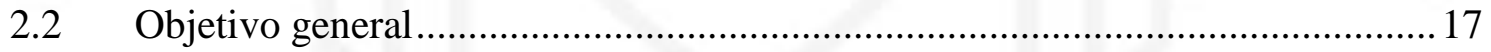

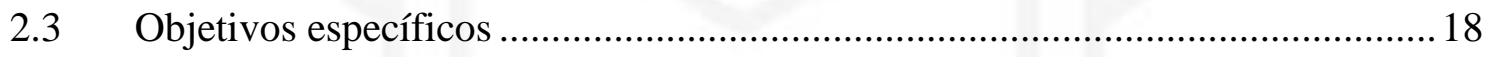

CAPÍTULO III. MARCO METODOLÓGICO .........................................................19

3.1 Metodología de recolección de la información................................................. 19

3.2 Metodología de análsis de la información ...................................................... 19

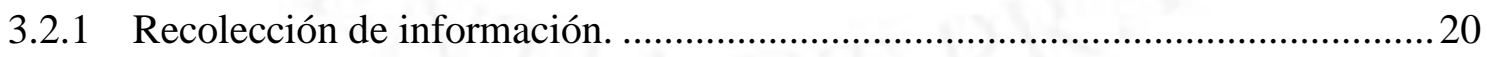

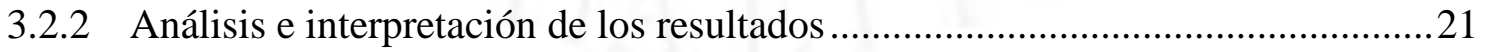

\section{CAPÍTULO IV. ANÁLISIS, PRESENTACIÓN Y DISCUSIÓN DE LOS}

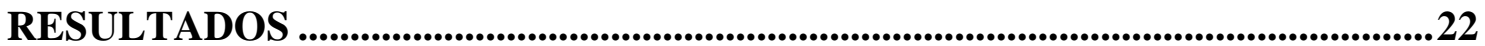

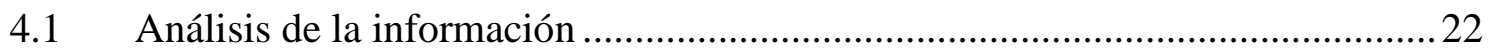

4.2 Presentación y discusión de los resultados ....................................................24

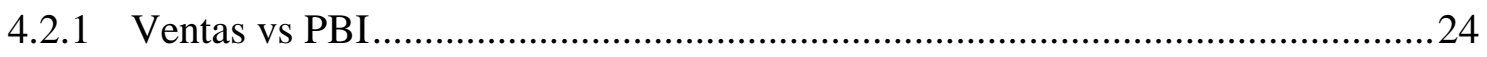




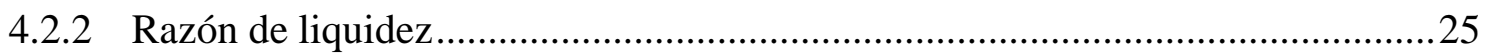

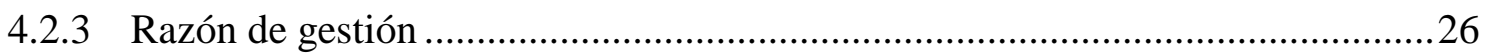

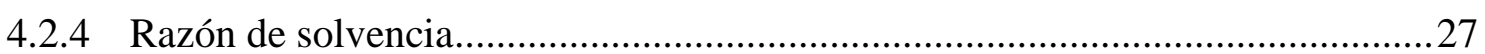

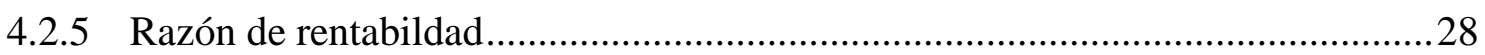

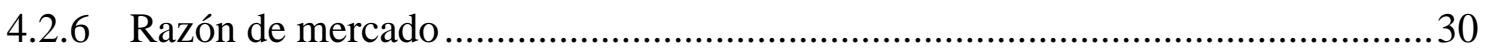

4.2.7 Supuestos de la proyección de los Estados Financieros periodo 2018 - 2022 ....31

4.2.8 Análisis de la proyección de los estados financieros ..........................................38

CAPÍTULO V. CONCLUSIONES Y RECOMENDACIONES.................................40

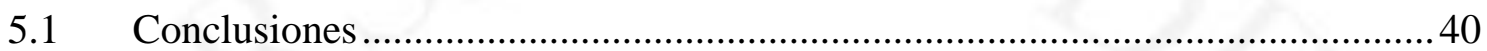

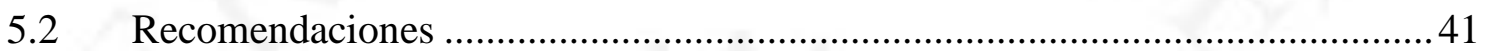

REFERENCIAS ..................................................................................................442

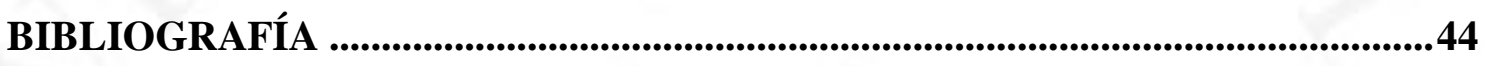

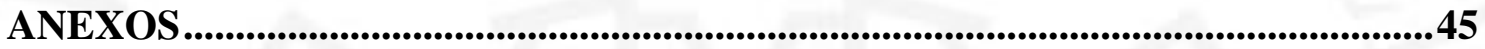




\section{ÍNDICE DE TABLAS}

Tabla 1. 1 Composición accionarial de Manufactura de Metales y Aluminio Record .....3

Tabla 1. 2 Distribución de la fuerza laboral..............................................................

Tabla 1. 3 Ventas en miles de soles por línea de producto ............................................5

Tabla 1. 4 Ventas de bienes y servicios en miles de soles Manufactura de Metales y

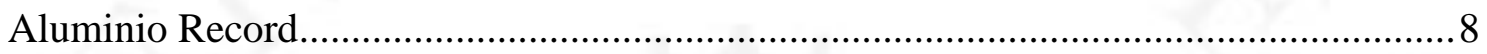

Tabla 1. 5 Principales competidores de Manufactura Record ......................................... 8

Tabla 1. 6 Matriz Peyea: Manufactura de Metales y Aluminio Record ......................... 15

Tabla 4. 1 Descripción de los Ratios aplicados a Manufactura de Record ......................23

Tabla 4. 2 Proyección del Estado de Situación Financiera Periodo 2018 - 2022 ........... 36

Tabla 4. 3 Proyección del Estado de Resultados del Periodo 2018 - 2022 ....................... 37

Tabla 4. 4 Proyección del Estado de Cambios en el Patrimonio Neto periodo 2018 - 2022 


\section{ÍNDICE DE FIGURAS}

Figura 1. 1 Organigrama de Manufactura de Metales y Aluminio Record ..................... 4

Figura 1. 2 Lista de precios de Record y competidores Extranjeros .............................

Figura 1. 3 Lista de precios de competidores Extranjeros ............................................

Figura 1. 4 Distribución canal mayorista de Manufactura Record ................................ 10

Figura 1. 5 Distribución canal moderno de Manufactura Record................................... 10

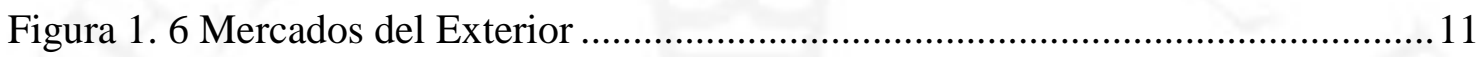

Figura 1. 7 Ferias y eventos de Manufactura Record ................................................. 11

Figura 1. 8 Cadena de valor de Manufactura de Metales y Aluminio Record ...............13

Figura 1. 9 Posición estratégica dentro del mercado .................................................. 14

Figura 4. 1 Ventas de Manufactura Record vs PBI ......................................................24

Figura 4. 2 Ventas de Manufactura Record por línea de producto ................................25

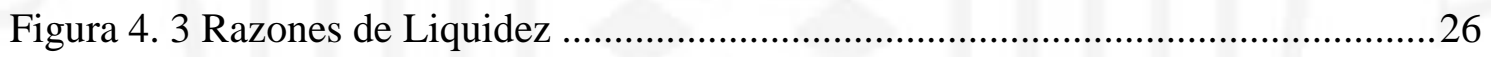

Figura 4. 4 Razones de Gestión ............................................................................ 27

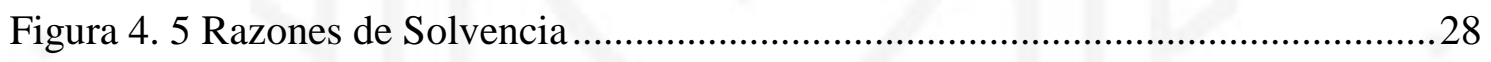

Figura 4. 6 Razón de Solvencia. Cobertura de Intereses ............................................28

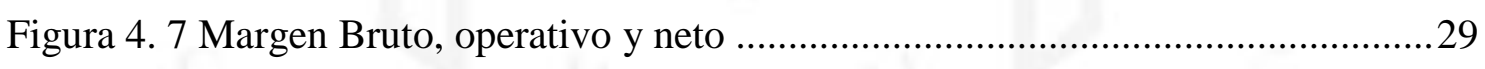

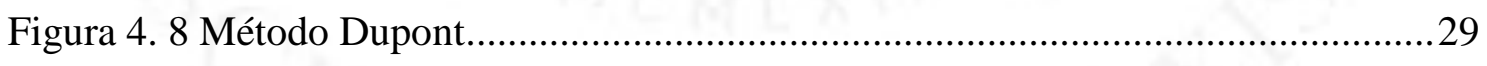

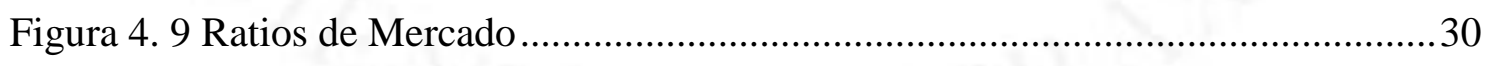

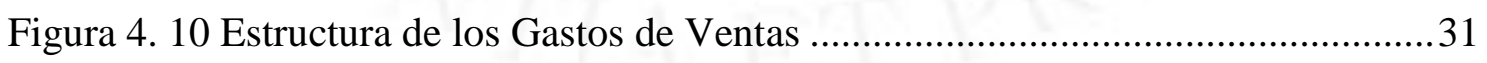




\section{ÍNDICE DE ANEXOS}

Anexo 1: Proyección del Estado de Situación Financiera periodo 2018-2022 .............. 46

Anexo 2: Proyección del Estado de Resultados periodo 2018-2022 ............................ 47

Anexo 3: Proyección del Estado de Cambios en el Patrimonio Neto periodo 2018-

2022 48

Anexo 4: Proyección del Estado de Flujos de Efectivo periodo 2018-2022 ................. 50

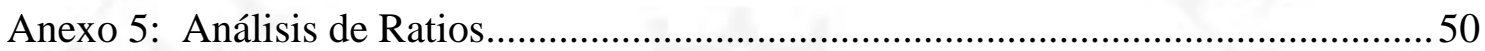




\section{INTRODUCCIÓN}

El presente trabajo de investigación tiene como finalidad realizar el estudio y evaluación de la influencia de los ratios financieros para la toma de decisiones de la empresa Manufactura de Metales y Aluminio Record S.A. periodo 2015-2017, para luego realizar el análisis y proyección de los estados financieros periodo 2018-2002.

La empresa Manufactura de Metales y Aluminio Record S.A. inició sus actividades el 17 de agosto de 1934 y se dedica a la manufactura de toda clase de artículos de metales, fierro, acero inoxidable, aluminio y materiales plásticos, así como la venta al público al por mayor y menor, teniendo una participación de $45 \%$ en su línea de utensilios para cocina (principalmente ollas y sartenes) y $65 \%$ en la línea de lavaderos.

El trabajo comienza definiendo en el capítulo I los antecedentes de la empresa en cuanto su estructura organizacional y su presencia en el mercado; en el capítulo II, se realiza una descripción del caso de investigación, se plantea el objetivo general y los objetivos específicos; en el capítulo III, se define el marco metodológico, tanto en la recolección de la información, como también en el análisis de la información; el capítulo IV, consta del análisis, discusión y presentación de los resultados, donde primero se analiza la información del trabajo y luego se presentan los resultados como la relación del PBI con la ventas de Manufactura de Metales y Aluminio Record S.A. y los ratios financieros en términos de liquidez, gestión, solvencia, rentabilidad y de mercado, luego se presenta los supuestos y análisis de la proyección de los estados financieros periodo 2018-2022. Por último, en el capítulo V, se señala las conclusiones y recomendaciones del trabajo además de bibliografía y anexos. 


\section{CAPÍTULO I. ANTECEDENTES DE MANUFACTURA DE METALES Y ALUMINIO RECORD S.A.}

\subsection{Historia, identificación y actividad económica de Manufactura de Metales y}

Aluminio Record S.A.

Record S.A. fue fundada el 17 de agosto de 1934, por don Federico Moll, Kurt Haustein y Willy Freitag, con el nombre de Fábrica de Aluminio Record S.A. Inició sus actividades con 14 trabajadores en el distrito de Breña, fabricando artículos de aluminio, lanzando al mercado su primera línea de ollas Duralum. Posteriormente, adicionó nuevos productos, tales como las ollas bombeada, ollas a presión, asaderas, sartenes y teteras (Manufactura de Metales y Aluminio Record S.A.[Record], s. f.).

En 1945 modifican la razón social a M. M. A. RECORD S.A., incluyendo el uso de otros metales, tales como: acero aporcelanado, acero inoxidable, cobre, etc.

En los años 1970 incorpora su línea de lavaderos y hasta hoy, es la única empresa fabricante de lavaderos (Record, s. f.).

Record S.A. se convirtió en la empresa líder en el mercado nacional en el rubro de utensilios y lavaderos, funcionando en dos plantas: Breña y (Los Frutales), aplicando en sus procesos productivos alta tecnología alemana y aseguramiento de la calidad en todas sus operaciones. El 22 de septiembre de 1995, unificó sus actividades empresariales en su planta de Av. Los Frutales, Ate en un área de 25000 m2. Desde el 2000 viene realizando alianzas estratégicas con empresas internacionales para representar sus marcas en el Perú.

La empresa de Manufactura de Metales y Aluminio Record S.A. participa en el mercado nacional con el $45 \%$ del mercado en utensilios y $65 \%$ en la línea lavaderos. Exporta sus productos a países, como Ecuador, Estados Unidos, Chile, Colombia, Venezuela, representando el $15 \%$ en el total de ventas.

En agosto 2011 amplió su portafolio, lanzó exitosamente su línea de electrodomésticos menores y en agosto del 2014 la línea de cocinas (Record, s. f.). 


\subsection{Estructura organizacional}

Manufactura de Metales y Aluminio Record S.A. cuenta con acciones comunes y de inversión que son de los trabajadores.

- Clases de acciones creadas y emitidas: Comunes y de Inversión.

- Capital Social del Emisor: El capital está representado por 25630,426 acciones comunes íntegramente suscritas y pagadas. Su valor nominal es de un nuevo sol por acción al 31 de diciembre del 2016.

- Acciones de Inversión: Corresponden a 9'601,839 acciones cuyo valor nominal es de un nuevo sol por acción y representan aproximadamente el 37\% del capital social al 31 de diciembre de 2016 (Record, 2017)

La estructura accionaria al 2016 tiene la siguiente composición:

Tabla 1.1

Composición accionarial de Manufactura de Metales y Aluminio Record S.A.

\begin{tabular}{||l|c|c||}
\hline \multicolumn{1}{|c|}{ Accionistas } & Participación \% & Nacionalidad \\
\hline Schwarz Moll, Walter & 15.91 & Alemana \\
\hline Freitag Nieland, Wolfgang & 14.51 & Peruana \\
\hline Haustein de Brescia, Elsa & 10.13 & Peruana \\
\hline Haustein de Bayer, Martha & 08.51 & Peruana \\
\hline Steixner Harrer, Helmut & 07.75 & Peruana \\
\hline Haustein de Podesta, Mary T. & 07.01 & Peruana \\
\hline v G. de Haustein, Alicia & 05.12 & Peruana \\
\hline
\end{tabular}

Fuente: Manufactura de Metales y Aluminio Record S. A. (2018) Elaboración propia

El presidente de Directorio es el ing. Walter Schwarz Moll, que cuenta con 8 años en el cargo. El gerente general es el MBA Wolfgang Freitag Nieland, que es además vicepresidente del Directorio. 
Figura 1. 1

Organigrama de Manufactura de Metales y Aluminio Record S.A.

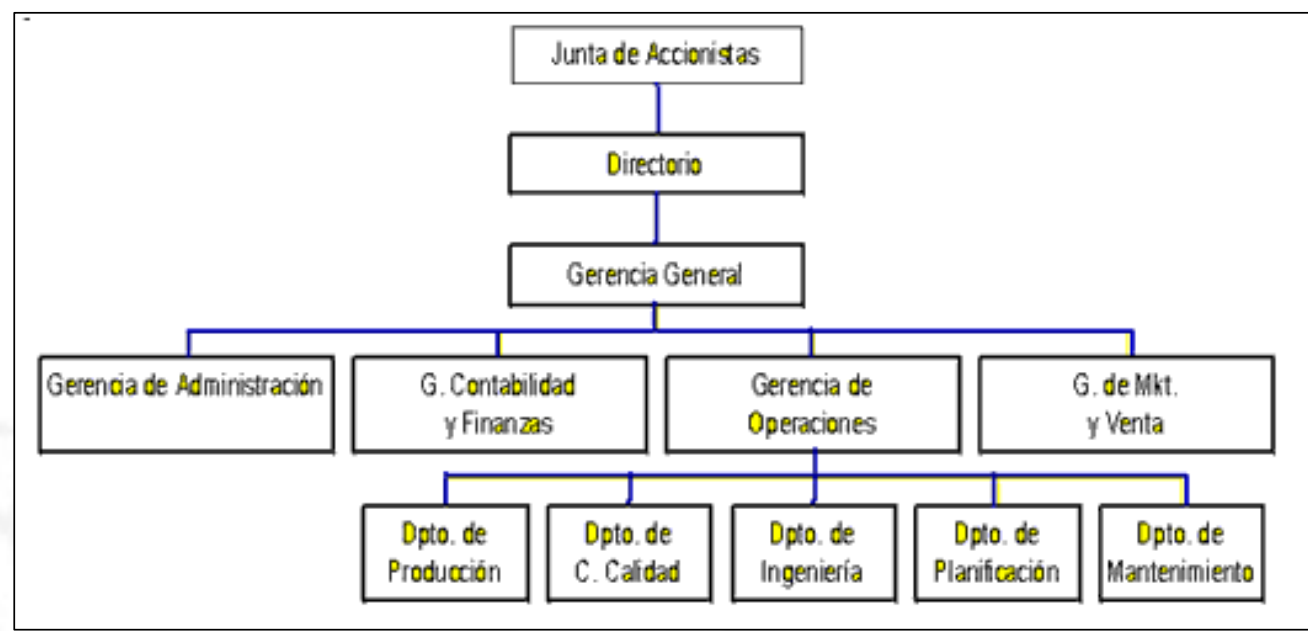

Fuente: Manufactura de Metales y Aluminio Record S. A. (2018)

Elaboración propia

\subsection{Aspectos organizativos y funcionales}

El 22 de septiembre de 1995, unificó sus actividades empresariales en su planta de la Av. Los Frutales, en el distrito de Ate, en un área de $25000 \mathrm{~m} 2$.

En el año 2016, la fuerza laboral ha estado integrada por 244 personas, representando una variación del $2 \%$ versus el 2015. Como se puede observar en la Tabla 1.2 , los obreros crecen en $3 \%$ y los empleados disminuyen en $-4 \%$.

Tabla 1.2

Distribución de la fuerza laboral

\begin{tabular}{|l|c|c|c|}
\hline \multicolumn{1}{|c|}{ Categoria } & $\mathbf{2 0 1 5}$ & $\mathbf{2 0 1 6}$ & Var.\% \\
\hline \hline Directores & 4 & 4 & $0 \%$ \\
Funcionarios & 9 & 8 & $-11 \%$ \\
Empleados & 50 & 48 & $-4 \%$ \\
Obreros & 175 & 181 & $3 \%$ \\
MFL - Practicante & 1 & 3 & $200 \%$ \\
\hline \multicolumn{1}{|c|}{ TOTAL } & $\mathbf{2 3 9}$ & $\mathbf{2 4 4}$ & $\mathbf{2 4}$ \\
\hline
\end{tabular}

Fuente: Manufactura de Metales y Aluminio Record S. A. (2018)

Elaboración propia 
Manufactura de Metales y Aluminio Record S.A. en el año 2016, afirmó su posición de líder en el mercado de utensilios y lavaderos, ya que alcanzó un crecimiento del $16 \%$ en su facturación versus el 2015 y además las ventas locales representaron el 92 $\%$ y las exportaciones el $8 \%$.

La categoría utensilios muestra un crecimiento del $30 \%$ versus el año anterior, principalmente por la venta en los canales promocional, institucional y exportación; siendo la línea de aluminio la que más aporta a través de los productos sartenes y ollas con recubrimiento antiadherente.

En la categoría lavaderos, como consecuencia de la contracción del sector construcción, se vendió $6 \%$ menos que el año 2015, evidenciado en el comportamiento de ambos canales (mayorista y moderno). Los consumidores, en su mayoría, siguen orientándose a productos de bajo precio que proceden principalmente de China y afectan al mercado de venta regular.

La línea electrodomésticos PEDS (importaciones) representa el 8\% del total de la venta, siendo el canal moderno y promocional, los que más han contribuido a esta venta ya que se incrementó en $20 \%$ (Tabla 1.3).

La facturación del año 2016 muestra un incremento del orden del $16.0 \%$ en relación con el año 2015, expresado en miles de soles. La variación responde a la venta promocional e institucional en la categoría de utensilios.

Tabla 1.3

Ventas en miles de soles por línea de producto

\begin{tabular}{|c|c|c|c|c|c|c|c|c|c|c|c|c|}
\hline \multirow{2}{*}{$\begin{array}{l}\text { Líneas de } \\
\text { produdtos }\end{array}$} & \multicolumn{3}{|c|}{ Siloon. 2015} & \multicolumn{3}{|c|}{ Si,000 2016} & \multicolumn{3}{|c|}{ Variación } & \multirow{2}{*}{$\begin{array}{l}\text { \%opart. } \\
2014 \\
\end{array}$} & \multicolumn{2}{|c|}{ \%art. $\triangle$ Patic. } \\
\hline & Propía & $\operatorname{lmp} p_{1}$ & Total & Propía & $\mid m p_{1}$ & Todal & Propia & $\operatorname{lmp} p_{1}$ & Tdal & & 2015 & $\%$ \\
\hline ALUMINNO & 14,350 & 3,774 & 18,124 & 18530 & 8,476 & 27,007 & $29 \%$ & $125 \%$ & $49 \%$ & $2623 \%$ & $33.66 \%$ & $7.44 \%$ \\
\hline ESMALTE & 9049 & 0 & 9,049 & 9,190 & 0 & 9,190 & $2 \%$ & $0 \%$ & $2 \%$ & $1309 \%$ & $11.46 \%$ & $-1,640$ \\
\hline AC. INOX & 8,560 & 3,368 & 11,928 & 11,654 & 2,916 & 14,571 & $36 \%$ & $-13 \%$ & $22 \%$ & $1726 \%$ & $18.16 \%$ & $0.90 \%$ \\
\hline PROD. POR BNCARGO & 0 & 0 & 0 & 0 & 0 & 0 & $0 \%$ & $0 \%$ & $0 \%$ & $0.00 \%$ & $0.00 \%$ & $000 \%$ \\
\hline TELONEADO YESMAL & 46 & 0 & 46 & 41 & 0 & 41 & $-11 \%$ & $0 \%$ & $-11 \%$ & $007 \%$ & $0.05 \%$ & $-0.02 \%$ \\
\hline LAVADEROS & 18210 & 4820 & 23,030 & 15,492 & 6,161 & 21,662 & $-15 \%$ & $28 \%$ & $-6 \%$ & $3333 \%$ & $26.99 \%$ & -63486 \\
\hline PEDS & 0 & 4819 & 4,819 & 0 & 6,092 & 6,092 & & $26 \%$ & 26 䋺 & $697 \%$ & $7.50 \%$ & $0.62 \%$ \\
\hline GEDS & 0 & 407 & 407 & 0 & 297 & 297 & $0 \%$ & $0 \%$ & $0 \%$ & $0,00 \%$ & $0.37 \%$ & $0.37 \%$ \\
\hline Sub-tota & 50,215 & 17,188 & 67,403 & 54,907 & 23942 & 78,849 & $9 \%$ & $39.3 \%$ & $17 \pi /$ & $9695 \%$ & $98.29 \%$ & $134 \%$ \\
\hline Desechos & 278 & 0 & 278 & 257 & & 257 & $-8 \%$ & $0 \%$ & -80 & $0.40 \%$ & $0.32 \%$ & $-0.08 \%$ \\
\hline Accesorios y Otros & 1,423 & 0 & 1,423 & 807 & 309 & 1,116 & $-43 \%$ & $0 \%$ & $-22 \%$ & $206 \%$ & $1.39 \%$ & $-0.670 /$ \\
\hline TOTAL & 51,916 & 17,188 & 69,104 & 56,971 & 24,251 & 80,222 & $\%$ & $41.1 \%$ & $16 \mathrm{P} / \mathrm{A}$ & $99.41 \%$ & $100.00 \%$ & $0.59 \%$ \\
\hline
\end{tabular}

Fuente: Manufactura de Metales y Aluminio Record S. A. (2018)

Elaboración propia 
Los proveedores foráneos más importantes de la empresa Manufactura de Metales y Aluminio Record S.A. (Perez, 2013), son:

1. Arcelormittal inox brasil S.A. ArcelorMittalInox Brasil es el principal productor de acero al silicio y acero de América del Sur. También produce de carbono y de acero aleado, barras gruesas, y tubos de acero inoxidable. Los productos de la compañía se utilizan como materia prima para piezas pesadas en camiones y tractores, electrodomésticos, y productos de construcción. ArcelorMittalInox Brasil mantiene una cuota de mercado nacional del 90\% para el acero inoxidable plana y productos de silicio. También exporta sus productos a más de 55 países. La compañía opera una planta de fabricación en el estado de Minas Gerais. Es una filial de \# 1 fabricante de acero del mundo, ArcelorMittal.

2. Industria Mexicana del Aluminio, S.A. de C.V. Se dedica a la producción y venta de productos de aluminio en México. La compañía ofrece bobinas de aluminio, hojas, círculos, y los productos que no se pegue. También exporta sus productos a Estados Unidos, Canadá y América Central. La compañía tiene su sede en Cuautitlán Izcalli, México. Hasta el 8 de marzo de 2007, Industria Mexicana del Aluminio, SA de CV es una subsidiaria de Ekco S.A. de CV.

3. Kasinda limited. De Hong-Kong, China Muebles Productos - Fabricante, Público. Es una empresa comercial y fabricante fundado en 1992, con la misión es brindar un servicio de calidad a los clientes. Cuenta con oficinas en Hong Kong (sede principal), Shenzhen, Guangzhou, Ningbo y Qingdao. Sus fábricas están localizadas en Shenzhen, Pingding y Samshui, Guangzhou y Qingdao, Shandong. HK Ltd. Nordic para hacer frente a las actividades de importación de EE.UU. nórdicos en Hong Kong y China. Agencia de Inspección en China de Jumbo SA de Argentina y Chile, que es el mayor minorista en Chile y Argentina.

Productos:

Fabricante de comedor de madera, artículos termómetro, mecedora, muebles de exterior, muebles para niños, linterna, tabla de planchar GlassBoat, mesa de 
madera curvada, muebles, taburete metal, juego de comedor, silla de oficina, escritorio de la computadora del metal, cama de madera, cama de aluminio, escalera, BBQ Navidad.

- Guangzhou Haojin Motorcycle Company Limited.

- Ingco Machinery Co., Limited.

- Reiner Kossmann International.

- Mcneil La Llc.

- Shaghai Pudong Import And Export Co.,Ltd.

- Reko Reiner Kossmann International.

- Shanghai Pudong Import. \& Exp. Co., Ltd.

\subsection{Presencia en el Mercado}

\subsubsection{Participación de Mercado de Manufactura de Metales y Aluminio Record} S.A.

La empresa Manufactura de Metales y Aluminio Record S.A. tiene una participación de $45 \%$ en su línea de utensilios para cocina (principalmente ollas y sartenes) y $65 \%$ en la línea de Lavaderos.

En la Tabla 1.4 se observa que el incremento de las ventas de Record en $16.1 \%$ de debe principalmente al incremento de las ventas de bienes: ventasen el mercado nacional de $89.7 \%$ y $89.9 \%$ en los años 2015 y 2016, respectivamente. La participación de sus exportaciones también se incrementó $8 \%$ año 2015 a $8.3 \%$ al año 2016. Por lo tanto, la empresa está en un proceso diversificación de sus ventas a nivel regional. Exporta sus productos a países, como Ecuador, Estados Unidos, Chile, Colombia, y Venezuela. 
Tabla 1.4

Ventas de bienes y servicios en miles de soles Manufactura de Metales y Aluminio Record S.A.

\begin{tabular}{|c|c|c|c|c|c|c|c|c|c|c|}
\hline \multirow[b]{2}{*}{ Destino } & & \multicolumn{4}{|c|}{ S/000 año 2015} & \multicolumn{4}{|c|}{ S/000 año 2016} & \multirow[b]{2}{*}{ Var \% Total } \\
\hline & & Propia & Importada & Total & $\%$ Total & Propia & Importada & Total & $\%$ Total & \\
\hline \multicolumn{11}{|c|}{ Venta de bienes } \\
\hline Nacional & & 50,133 & 11,867 & 62,000 & $89.7 \%$ & 48,769 & 23,379 & 72,148 & $89.9 \%$ & $16.4 \%$ \\
\hline exterior & & 5,226 & 333 & 5,559 & $8.0 \%$ & 6,098 & 564 & 6,662 & $8.3 \%$ & $19.8 \%$ \\
\hline Venta de & cios & & & - & & & & - & $0 . \%$ & \\
\hline Nenta de s & Cius & 90 & & 90 & $0.1 \%$ & 41 & & 41 & $\begin{array}{l}0.0 \% \\
0.1 \%\end{array}$ & $-54.4 \%$ \\
\hline \multicolumn{11}{|c|}{ Otras Ventas local } \\
\hline Desechos & & 306 & & 306 & $0.4 \%$ & 257 & & 257 & $0.3 \%$ & $-16.0 \%$ \\
\hline \multicolumn{2}{|c|}{ Accseorios otros } & 817 & 332 & 1,149 & $1.7 \%$ & 807 & 309 & 1,116 & $1.4 \%$ & $-2.9 \%$ \\
\hline Total & & 56,572 & 12,532 & 69,104 & $100.0 \%$ & 55,972 & 24,252 & 80,224 & $100.0 \%$ & $16.1 \%$ \\
\hline
\end{tabular}

Fuente: Manufactura de Metales y Aluminio Record S. A. (2018)

Elaboración propia

\subsubsection{Competidores}

Como se puede apreciar en la Tabla 1.5, las empresas nacionales que compiten con Record son micros y pequeñas empresas como La Moderna, Reymon Ollas, Ciesa Industria ( Industria Ciesa, s.f.), etc., y sus puntos de ventas son los canales tradicionales, mercados y tiendas de productos para la cocina. La empresa Rena Ware que también ofrece productos para la cocina su estrategia de ventas es al menudeo a través de micro comercializadores en los diferentes distritos de Lima (Paginas amarillas, s.f.). En cambio, en el canal moderno de supermercados compite con marcas extranjeras como Tramontina de Brasil, Teka e ILKO de Chile, etc.

Tabla 1.5

Principales competidores de Manufactura de Metales y Aluminio Record S.A.

\begin{tabular}{|c|c|c|c|c|}
\hline \multirow{2}{*}{ Empresas } & \multirow[b]{2}{*}{ Pais } & \multicolumn{2}{|c|}{ Utencilios } & \multirow[b]{2}{*}{ Lavaderos } \\
\hline & & Ollas & Sartenes & \\
\hline Record & Perú & $45 \%$ & $45 \%$ & $65 \%$ \\
\hline la Moderna & Perú & $x$ & $\mathrm{X}$ & \\
\hline Rena Ware & USA & $x$ & $x$ & 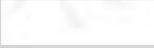 \\
\hline Reymon Ollas & Perú & $X$ & $X$ & \\
\hline Ciesa Industria & Peru & $x$ & $x$ & \\
\hline Metalicas Eternas & Peru & $x$ & $x$ & \\
\hline Teka Chile & Chile & & & $x$ \\
\hline Tramontina & Brasil & $x$ & $x$ & $x$ \\
\hline Virutex ILKO & Chile & $x$ & $x$ & \\
\hline
\end{tabular}

Fuente: Páginas amarillas (s.f.)

Elaboración propia 
Como muestra de la alta competencia que tiene Record con sus competidores extranjeros en el canal Moderno de supermercados. En la Figura 1.2, en la lista de precios de Saga Falabella se puede aprecia que un set de ollas de acero inoxidable de 6 piezas tiene un precio de lista de S/. 459, mientras que la marca Tramontina (Brasil) ofrece un juego de ollas con las mismas características, pero un juego de 8 piezas a S/. 489, con lo cual el precio de Record es relativamente más alto. De la misma manera sucede en su línea de lavaderos de cocina (Tramontina, 2017).

Figura 1.2

Lista de precios de Record y competidores Extranjeros

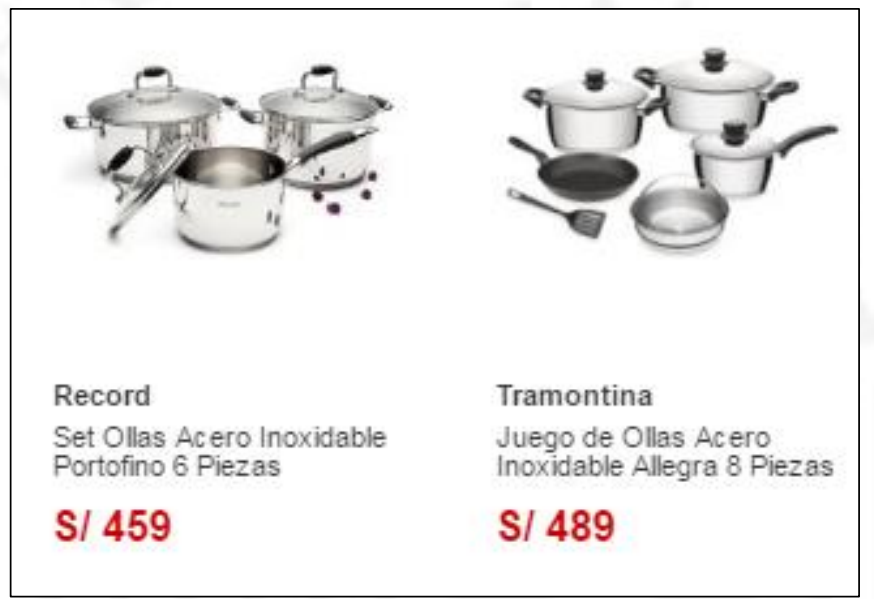

Fuente: Mercado Libre (s.f.)

Figura 1.3

Lista de precios de competidores extranjeros

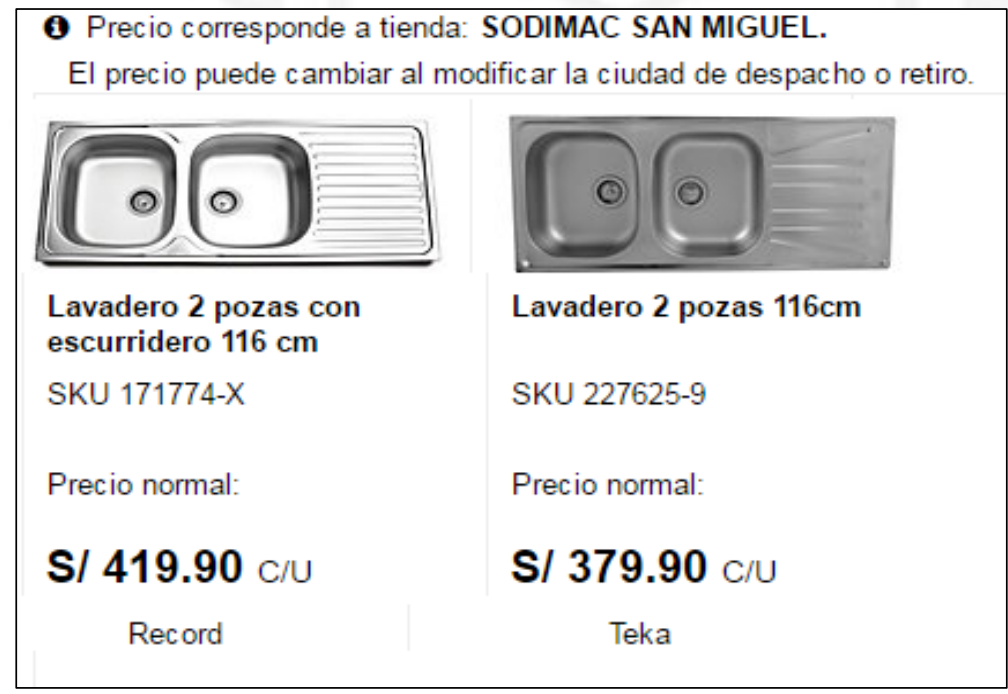

Fuente: Sodimac (s.f.) 


\subsubsection{Principales clientes}

Manufactura de Metales y Aluminio Record S.A. cuenta con diferentes productos de cocina: utensilios, electrodomésticos, lavaderos y cocinas; con una cadena de distribución canal mayorista por todo el Perú (Figura 1.4)

Figura 1.4

Distribución canal mayorista de Manufactura de Metales y Aluminio Record S.A.

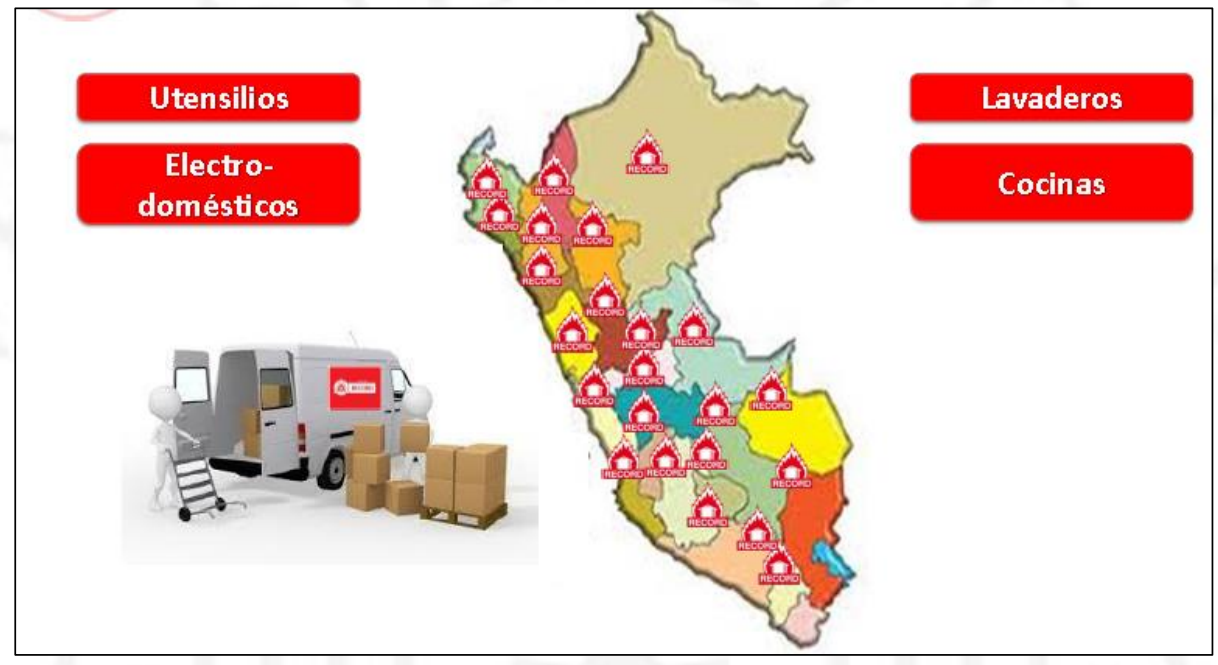

Fuente: Manufactura de Metales y Aluminio Record S. A. (2018)

La forma de distribución que Manufactura de Metales y Aluminio Record S.A. realiza con sus productos en el Canal Moderno se caracteriza porque la parte de utensilios lo realiza a través de Saga Falabella, Ripley, Hiraoka, etc. En cambio, lo correspondiente a lavaderos se realiza a través de Sodimac, Promart, Ace Home Center, etc. (Figura 1.5)

Figura 1.5

Distribución canal moderno de Manufactura de Metales y Aluminio Record S.A.

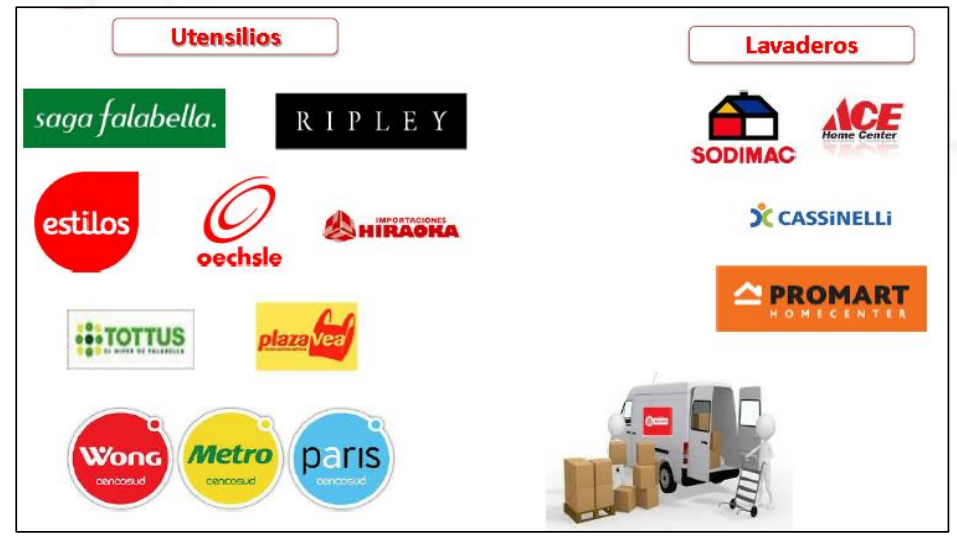

Fuente: Manufactura de Metales y Aluminio Record S. A. (2018) 
La alta calidad de los productos y servicios de Manufactura de Metales y Aluminio Record S.A., ha permitido a la empresa expandir sus ventas al exterior, y en el año 2016 representó el $8.3 \%$ de sus ventas totales. La estrategia de diversificación Regional de Record le ha permitido a la empresa penetrar en países como Bolivia, Chile, Ecuador Colombia, Costa Rica y USA.

Figura 1.6

Mercados del Exterior

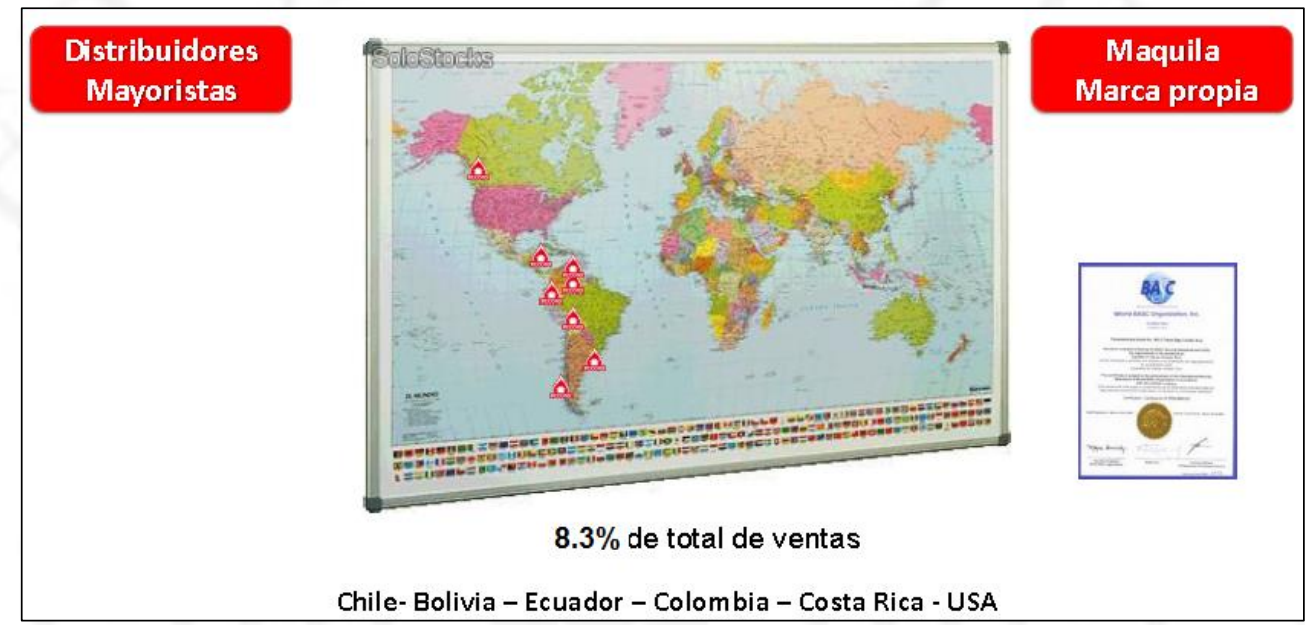

Fuente: Manufactura de Metales y Aluminio Record S. A. (2018)

Como parte de estrategia de Marketing, Manufactura de Metales y Aluminio Record S.A. también realiza ferias y eventos como la feria de gastronomia peruana Mistura y la feria de las tendencia de construccion Excon.

Figura 1.7

Ferias y eventos de Manufactura de Metales y Aluminio Record S.A.

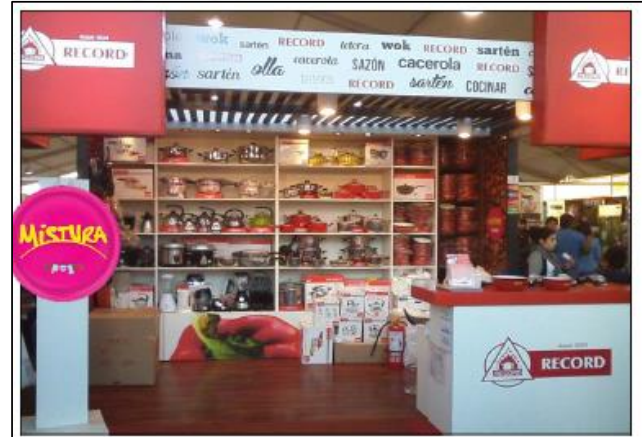

MISTURA

Feria de la gastronomía peruana.

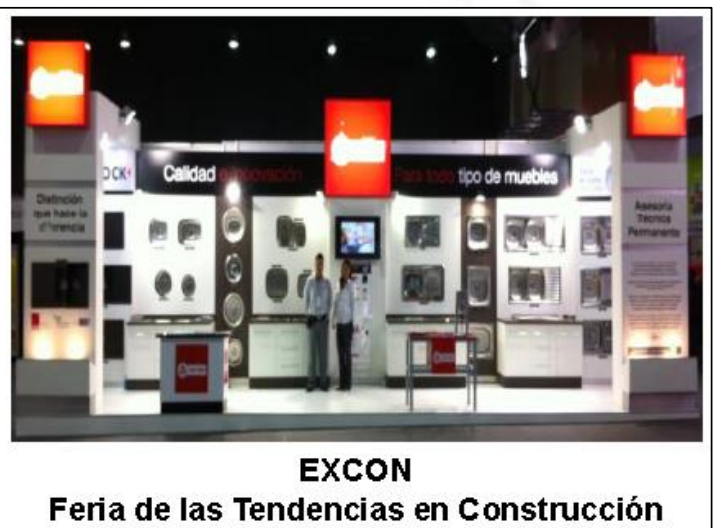

Feria de las Tendencias en Construcción

Fuente: Manufactura de Metales y Aluminio Record S. A. (2018) 


\subsubsection{Análisis FODA}

1. Fortalezas

$\checkmark \quad$ Entrega de pedidos a tiempo.

$\checkmark \quad$ Buena calidad y a bajo precio.

$\checkmark \quad$ Vendedores con conocimiento del mercado.

$\checkmark$ Buen trato a sus clientes y trabajadores.

$\checkmark \quad$ Fidelización del cliente con la marca.

$\checkmark$ Investigación y desarrollo de proyectos o diseños de nuevos productos o artículos.

$\checkmark \quad$ Mano de obra experimentada.

$\checkmark$ Apertura a las sugerencias de cualquier índole provenientes de cualquier persona.

2. Oportunidades

$\checkmark \quad$ La comercialización de productos en nuevos mercados.

$\checkmark$ Crecimiento del mercado con el diseño de nuevos productos.

$\checkmark \quad$ Alianzas estratégicas con distribuidores y comercializadores.

$\checkmark$ Crecimiento de las exportaciones en nuevos países de la región.

3. Debilidades

$\checkmark \quad$ Falta de capacitación continua (operadores de la planta). 
$\checkmark \quad$ Falta de retroalimentación continúa de los clientes.

$\checkmark \quad$ Falta de espacio en la planta de producción y almacenes.

4. Amenazas

$\checkmark$ Empeoramiento de la situación económica del país.

$\checkmark \quad$ El incremento de nuevos productos de la competencia.

$\checkmark$ Contrabando: falta de control de importaciones.

$\checkmark \quad$ Mayor aceptación de productos sustitutos.

$\checkmark \quad$ Recesión económica a nivel mundial.

\subsubsection{Cadena de valor de la empresa}

Figura 1.8

Cadena de valor de Manufactura de Metales y Aluminio Record S.A.

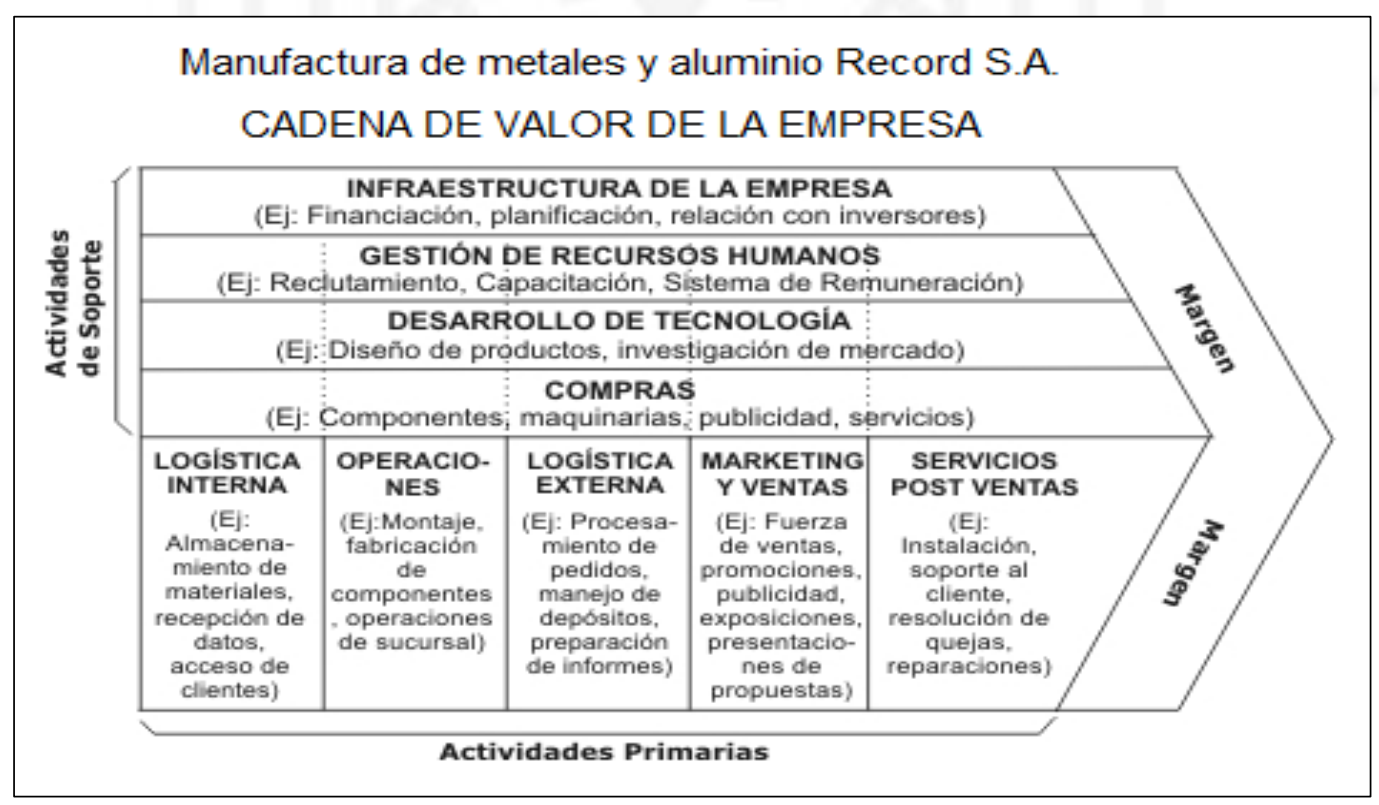

Fuente: ¿Qué es una cadena de valor? (2015) 


\subsubsection{Evaluación de la posición estratégica de la empresa}

La posición estrategia de Manufactura de Metales y Aluminio Record S.A. dentro de su mercado es conservadora ya que el vector direccional apunta al cuadrante superior izquierdo de la matriz. (Figura 1.9).

Figura 1.9

Posición estratégica dentro del mercado

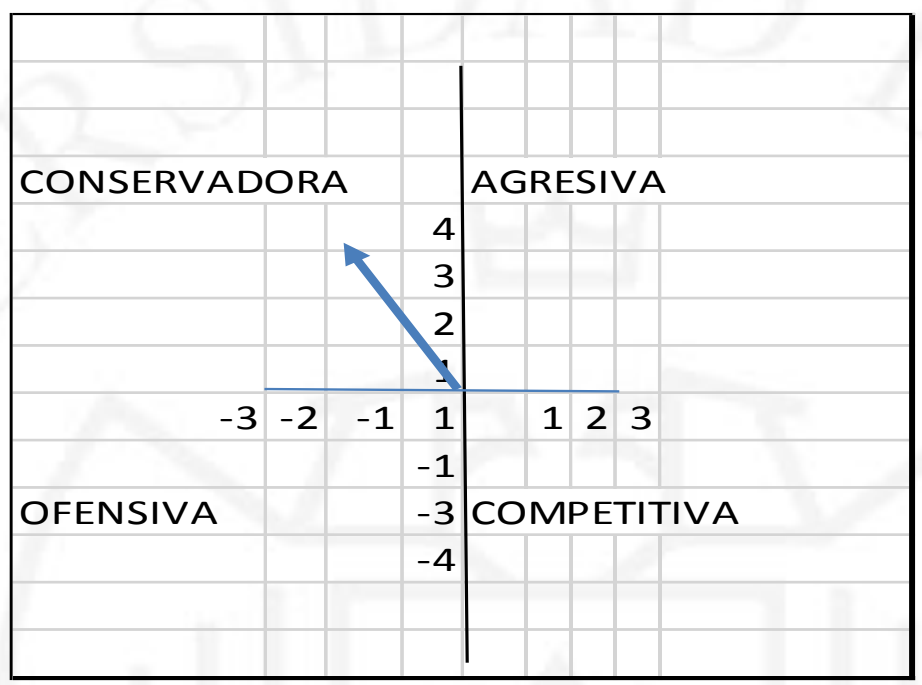

Fuente: Elaboración propia

Lo cual implica que la posición estratégica de la empresa es permanecer dentro de las habilidades básicas de la firma sin tomar riesgos excesivos. Esta estrategia está en relación a que la empresa está desarrollando mayor penetración de mercado a nivel de países de la región; a su vez, desarrollo de nuevos productos para la cocina y servicios a empresas dentro de una diversificación concéntrica. 
Tabla 1.6

Matriz Peyea: Manufactura de Metales y Aluminio Record S.A.

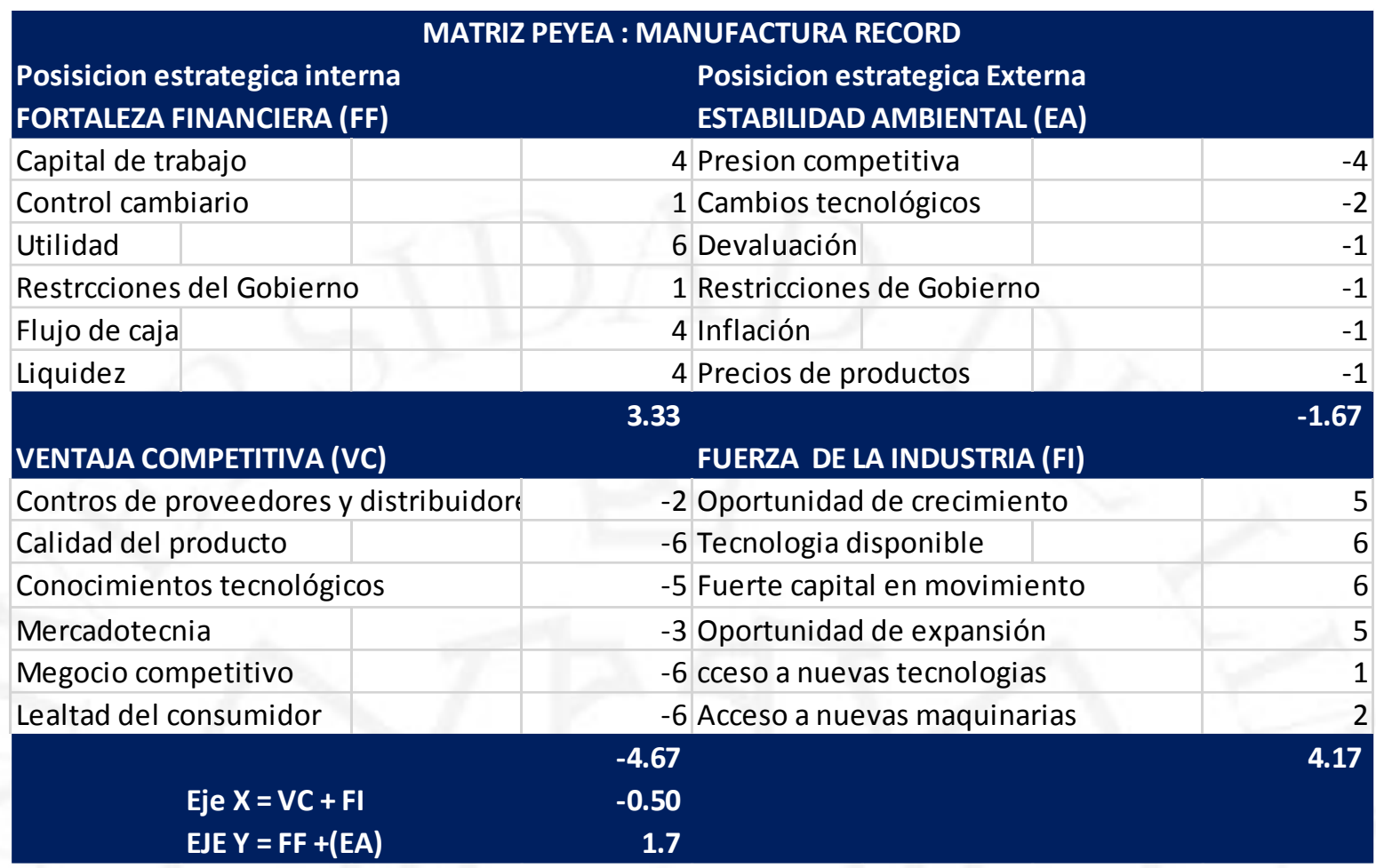

Fuente: Elaboración propia 


\section{CAPÍTULO II. DESCRIPCIÓN Y OBJETIVOS DEL TRABAJO DE SUFICIENCIA PROFESIONAL}

\subsection{Descripción del caso de investigación}

El diagnóstico y el pronóstico de la situación financiera que realizan las empresas a través de los ratios financieros influyen en las decisiones de gestión en términos de inversiones y financiamiento de corto plazo (capital de trabajo) como de largo plazo y de esta manera puedan mejorar sus ingresos y rentabilidad.

Manufactura de Metales y Aluminio Record S.A. es una empresa de productos metálicos donde el $62 \%$ de su total de ventas son utensilios para el hogar y el $31 \%$ son lavaderos.

También del total de sus ventas $40 \%$ se canaliza en el canal mayorista, $36 \%$ canal moderno, $8 \%$ ventas al exterior y $12 \%$ canal institucional.

En el año 2017, Manufactura de Metales y Aluminio Record S.A., tuvo una disminución de sus ventas totales en $-6 \%$ con respecto al año 2016. Las causas de esta disminución de sus ventas se deben a que el entorno económico tiene mucha incertidumbre debido al escándalo Lava Jato y al fenómeno del niño que afectaron la demanda del consumidor. Hay que señalar también que Manufactura de Metales y Aluminio Record S.A. está sujeto a una alta competencia de productos chinos y de contrabando.

Es por ello que el trabajo de investigación propone identificar: primero, aquellos ratios financieros que se puedan aplicar a Manufactura de Metales y Aluminio Record S.A. de acuerdo a las características propias de la empresa, complementando dicho análisis con el método Dupont, evaluación del Estado de Flujos de Efectivo de la empresa, Estado de Cambios en el Patrimonio Neto y análisis vertical y horizontal; segundo, realizar la proyección de los Estados Financieros para llegar a conclusiones y recomendaciones que permita de esta manera ayudar a la administración de manufactura Record a tomar decisiones en términos de capital de trabajo, niveles de liquidez, solvencia y rentabilidad. 
El análisis mediante ratios financieros nos va a permitir determinar la situación financiera de la empresa para los años del 2015 al 2017, en términos de liquidez, gestión, solvencia, rentabilidad e indicadores de mercado. Se complementará este análisis con el Estado de Flujos Efectivo y el Estado de Cambio en el Patrimonio importante porque por ejemplo la razón de deuda se incrementó en el año 2017, por incremento de la Deuda de Corto y largo plazo; el estado de flujos de efectivo nos dio información sobre el uso del incremento de la Deuda que en este caso fue para el pago de dividendos y recompra de acciones de inversión

Una vez realizado el diagnostico financiero de la empresa Manufactura de Metales y Aluminio Record S.A., se llevará a cabo la proyección de los cuatro Estados Financieros de acuerdo a la NIC 1 periodo 2018-2022; para ello haremos uso del análisis vertical para el estado de la situación financiera y del análisis vertical y horizontal para el estado de resultados. De dicha proyección se obtuvo de acuerdo al análisis horizontal del estado de resultados una tasa de crecimiento promedio de $3.07 \%$ para los próximos cincos años. Por el nivel alto de deuda y una cobertura de intereses bajo - menos de $3 \mathrm{x}$ (veces) - alcanzado por Manufactura de Metales y Aluminio Record S.A. al año 2017, y un entorno económico interno de alto riesgo financiero para los próximos años por incremento de la tasa de interés por parte de la FED en Estados Unidos se ha planteado en el pronóstico financiero que la empresa haría uso del financiamiento con capital propio en vez del uso de la Deuda para el financiamiento sus inversiones de capital importante para que la empresa mantenga sus productos diferenciados de la competencia, sobre todo en la línea de utensilios para el hogar. Haciendo uso del Financiamiento con capital propio la empresa disminuiría su riesgo financiero por la mejora de la cobertura de intereses más de $3 x$.

\subsection{Objetivo general}

Analizar la situación financiera mediante la aplicación de ratios financieros y determinar la proyección de los estados financieros para el periodo 2018-2022, para la toma de decisiones de Manufactura de Metales y Aluminio Record S.A. 


\subsection{Objetivos específicos}

$\checkmark \quad$ Identificar los ratios de liquidez, actividad, solvencia y rentabilidad y de mercado para analizar la situación financiera de Manufactura de Metales y Aluminio Record S.A.

$\checkmark$ Evaluar si la empresa Manufactura de Metales y Aluminio Record S.A. presenta adecuados niveles de Solvencia, Liquidez, Gestión, Rentabilidad y de Mercado. (upa, valor contable por acción).

$\checkmark$ Aplicar mediante el método Dupont la rentabilidad de los activos (ROA) y rentabilidad del Patrimonio (ROE).

$\checkmark \quad$ Aplicar el análisis vertical y horizontal de la empresa Manufactura de Metales y Aluminio Record S.A.

$\checkmark$ Proyectar y analizar los estados financieros: Estado de Situación Financiera, Estado de Resultados, Estado de Flujos de Efectivo y Estado de Cambios en el Patrimonio Neto de Manufactura de Metales y Aluminio Record S.A. 


\section{CAPÍTULO III. MARCO METODOLÓGICO}

\subsection{Metodología de recolección de la información}

Se aplicará el método de análisis sintético ya que se analizará la situación financiera con ratios financieros y luego se proyectará los cuatro estados financieros: Estado de Situación Financiera, Estado de Resultados, Estado de Cambios en el Patrimonio Neto y Estado de Flujos de Efectivo con la finalidad que la empresa Manufactura de Metales y Aluminio Record S.A. tome la mejor decisión en términos de liquidez, gestión del ciclo de caja, solvencia y rentabilidad.

La técnica empleada fue la recolección de datos secundarios, teniendo como fuente de información la Bolsa de Valores de Lima (BVL) del cual se obtuvo:

1. Estados Financieros auditados de Manufactura de Metales y Aluminio Record S.A. según la NIC 1: Estado de Situación Financiera, Estado de Resultados, Estado de Cambios en el Patrimonio Neto y el Estado de Flujos de Efectivo para los años 2015 - 2016.

2. Memoria de Manufactura Record S.A. para los años 2015, 2016 y 2017.

3. Notas de los estados financieros auditados para los años 2015, 2016 y 2017.

4. Boletín de la Bolsa de Valores de Lima.

También se obtuvo de otras fuentes secundarias como:

- Página web de la empresa Manufactura de Metales y Aluminio Record S.A.

- Clasificadoras de Riesgo.

- Diarios, revistas y redes sociales.

\subsection{Metodología de análisis de la información}

El siguiente esquema describe el método de análisis de la información: 


\subsubsection{Recolección de información.}

La obtenemos principalmente de la Bolsa de Valores de Lima (BVL), en la opción empresas de la BVL y situación financiera donde se obtuvo los cuatro Estados Financieros de Manufactura de Metales y Aluminio Record S.A. para los años 2015 al 2017. De igual manera del Boletín de la BVL se obtuvo los precios de mercado de la empresa como la frecuencia de negociación. De las notas de los Estados financieros aplicar las explicaciones de las cuentas de los estados financieros como por ejemplo a la estructura de los gastos de ventas que afecta la rentabilidad y cobertura de intereses.

1. Preparación de la información en Excel. Una vez obtenida la información de los Estados Financieros se procedió a realizar el análisis vertical de la situación financiera y el análisis vertical y horizontal del Estado de Resultados. De la misma Manera la estimación de los ratios de liquidez, gestión, solvencia, rentabilidad y de mercado. También se realizó la proyección de los estados financieros sobre la base de los datos históricos para los años 2008 al 2022 con la finalidad de proponer soluciones en términos de Liquidez, solvencia, rentabilidad e indicadores de mercado.

2. Aplicación de las Técnicas de Diagnóstico Financiero para la empresa Manufactura de Metales y Aluminio Record S.A.

- Análisis Vertical del Estado de Situación Financiera y Estado de Resultados. Principalmente para el análisis de los ratios y como base para la proyección de los estados financieros.

- Análisis de Ratios Financieros.

- Análisis del Estado de Flujos de Efectivo. Importante porque nos explica los usos y fuentes de fondos y que se complementan con el análisis de ratios.

- Análisis del Estado de Cambios en el Patrimonio Neto. Nos permite determinar que cuentas definen el cambio patrimonial como en el caso de Manufactura de Metales y Aluminio Record S.A. en el año 2016 se realizó una revaluación de inmuebles y equipo. 
- Proyección y Análisis de los estados financieros para los próximos cinco años 2018 - 2022. Con la finalidad de tome la mejor decisión en términos de nivel de Deuda ya que la empresa presenta una cobertura de intereses por debajo de 3x en el año 2017. Una situación de alto riesgo financiero para la empresa en un entorno donde los países emergentes como el Perú corre el peligro de incremento de la tasa de interés como consecuencia de la política de incremento de la tasa de referencia de la FED.

\subsubsection{Análisis e interpretación de los resultados}

La limitación que presenta el análisis e interpretación con ratios financieros es que es una parte del diagnóstico integral de la empresa Manufactura de Metales y Aluminio Record S.A. Además del análisis financiero con ratios se debe analizar aspectos organizacionales, jurídicos, comerciales, tecnológicos, laborales etc. 


\section{CAPÍTULO IV. ANÁLISIS, PRESENTACIÓN Y DISCUSIÓN DE LOS RESULTADOS}

\subsection{Análisis de la información}

Se hará uso tanto del análisis cuantitativo, cualitativo y de gráficos de la información de los Estados Financieros auditados de Manufactura de Metales y Aluminio Record S.A. para los años terminados del 2015 al 2017, obtenidos de la Bolsa de Valores de Lima.

Se hará uso del análisis vertical tanto en el Estado de Situación Financiera como en el Estado de Resultados de Manufactura de Metales y Aluminio Record S.A. con la finalidad de conocer la estructura de las inversiones y financiamiento en el caso del Estado de Situación financiera y de la estructura de costos para el Estado de Resultados.

De igual manera del Estado de Situación Financiera y del Estado de Resultados se hará uso la siguiente clasificación de Ratios para aplicarlo a Manufactura de Metales y Aluminio Record S.A.

Para realizar el análisis de ratios de Manufactura de Metales y Aluminio Record S.A. se ha dividido en 5 grupos como son: Ratios de liquidez, gestión, solvencia, rentabilidad y de mercado como también se ha aplicado el método Dupont para explicar el comportamiento del ROE y el ROA. 
Tabla 4. 1

Descripción de los Ratios aplicados a Manufactura de Metales y Aluminio Record S.A.

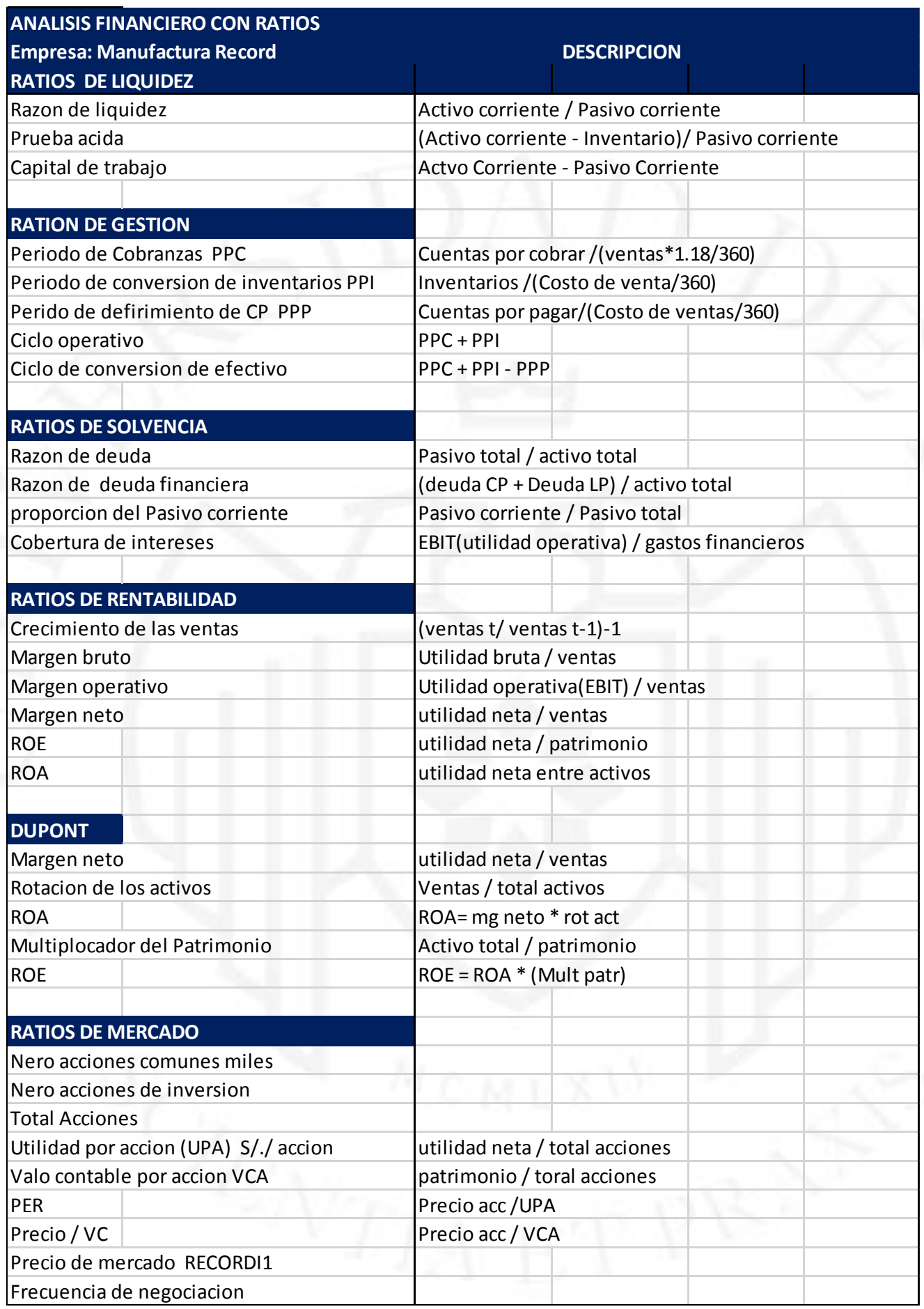

Fuente: Elaboración propia 
4.2 Presentación y discusión de los resultados

\subsubsection{Ventas vs PBI}

Las ventas de Manufactura de Metales y Aluminio Record S.A. crecieron a un nivel de $16.1 \%$ en el año 2016, explicado por el incremento del PBI de 4 \%. El año 2016 se caracterizó por el desarrollo de grandes proyectos como: Línea 2 de metro de Lima, Gaseoducto Sur, etc. En cambio, en el año 2017 el PBI disminuyo a $2.5 \%$, como consecuencia principalmente del caso lava jato y el niño costero que también impactaron negativamente a las ventas de manufactura record que disminuyó -5.6 \% (ver Figura 4.1)

\section{Figura 4. 1}

Ventas de Manufactura de Metales y Aluminio Record S.A. vs PBI

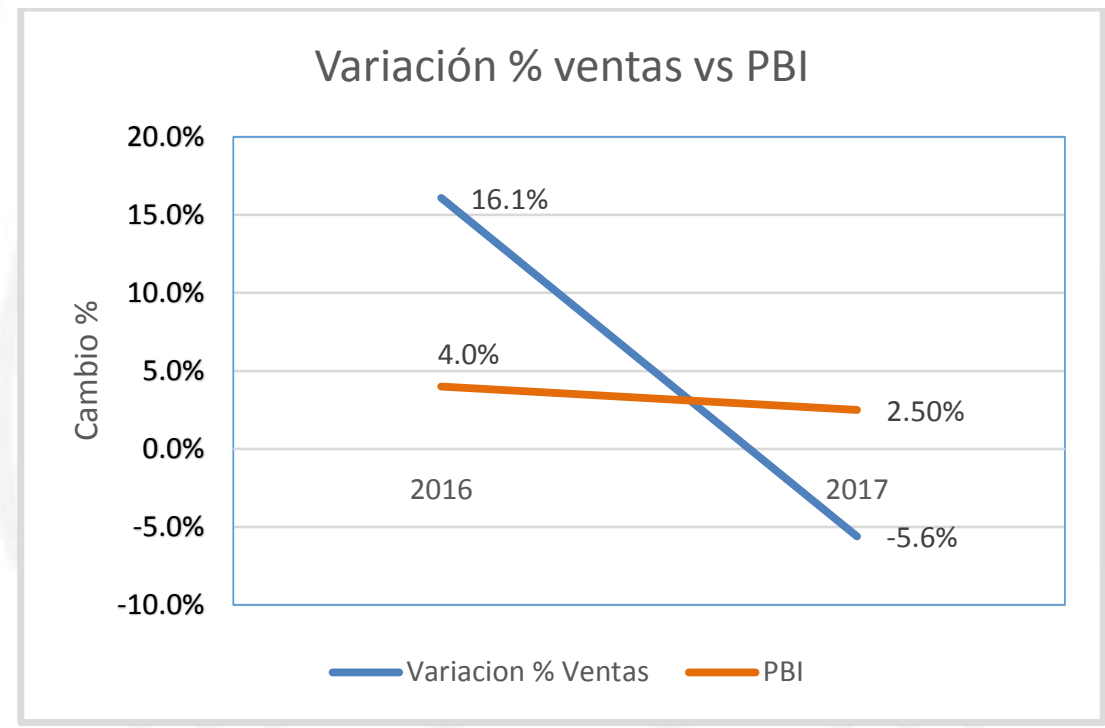

Fuente: Bolsa de Valores de Lima (2017)

Elaboración propia

Las ventas más importantes por línea de producto de Manufactura de Metales y Aluminio Record S.A. son utensilios de aluminio que tuvo un incremento de $49 \%$ en el año 2016 y una disminución de $-11 \%$ en el año 2017 y lavaderos que disminuyo en -6 \% en el año 2016 y subió $8 \%$ en el año 2017, compensado de alguna manera la caída de las ventas de utensilios de aluminio (ver Figura 4.2) 
Figura 4. 2

Ventas de Manufactura de Metales y Aluminio Record S.A. por línea de producto

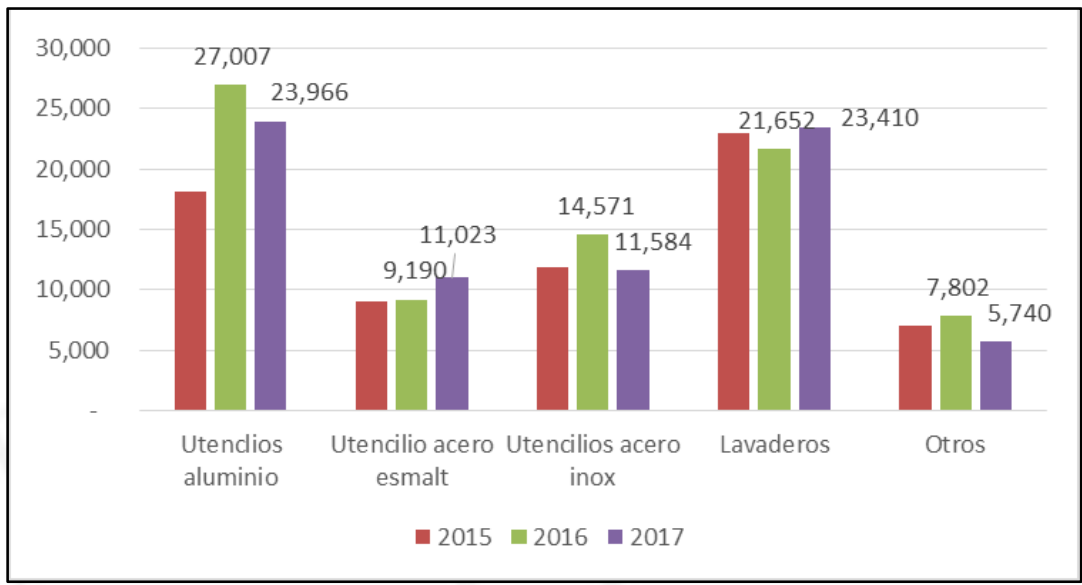

Fuente: Bolsa de Valores de Lima (2017)

Elaboración propia

\subsubsection{Razón de liquidez}

La razón de liquidez aumenta de 1.68 año 2015 a 2.0 año 2016, como consecuencia de la disminución de las cuentas por pagar a comerciales que paso de $8.8 \%$ a $3.9 \%$ (como porcentaje de las ventas) en los años 2015 y 2016 respectivamente (ver Anexo 1), como consecuencia de la disminución del crédito de proveedores principalmente de acero y aluminio para la producción de ollas y lavaderos, como también por la adquisición de bienes para la venta de electrodomésticos pequeños.

Para el año 2017 la liquidez disminuye a 1.83 como consecuencia del incremento de del financiamiento con bancos en el corto plazo que paso de $6.7 \%$ a $8.9 \%$ años 2016 y 2017 respectivamente. Este incremento de la deuda de corto plazo según el Estado de Flujos de Efectivo se debe como parte del pago de dividendos y la recompra de acciones de inversión (Anexo 4).

Manufactura de Metales y Aluminio Record S.A. al mantener niveles altos de inventarios (anexo 1) con la finalidad de atender clientes y ventas promocionales de comienzos de año hace que la prueba acida disminuya a menos de la mitad respecto al ratio de liquidez con lo cual afecta negativamente su solvencia de corto plazo (ver Figura $10)$. 
Figura 4.3

Razones de Liquidez

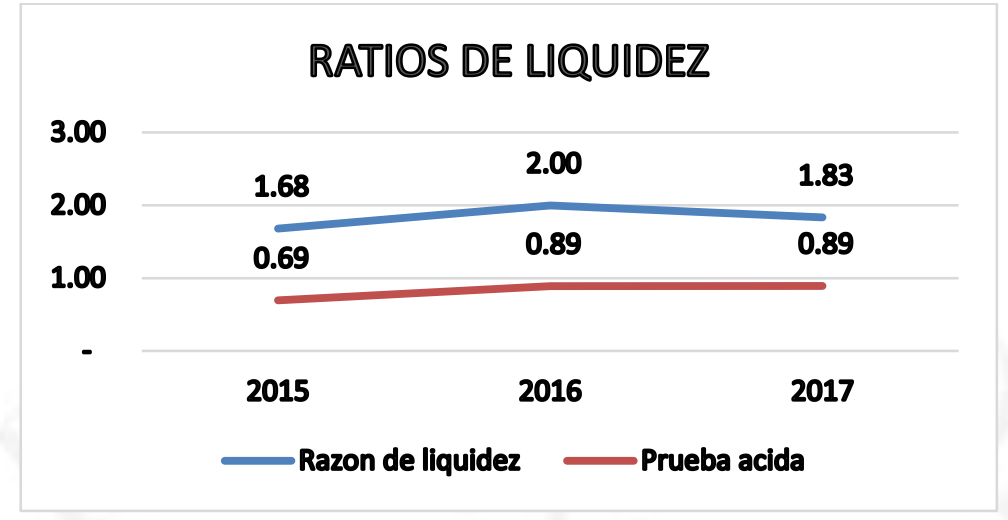

Fuente: Bolsa de valores (2017)

Elaboración propia

\subsubsection{Razón de gestión}

La empresa Manufactura de Metales y Aluminio Record S.A. alcanza su mejor nivel de ciclo de conversión de efectivo (CCE) en el año 2016 con 199 días de financiamiento de capital de trabajo. Esto como consecuencia de una disminución importante del periodo de conversión de inventarios (PCI) de 237 días en el año 2015 a 184 días en el año 2016. También mejoró el periodo promedio de cobranzas (PPC) con clientes de 72 a 65 días, pero disminuyó el periodo de pago con proveedores (PPP) de 100 días, a 51 días por la exigencia de los proveedores de materiales para la producción de ollas y lavaderos (ver gráfico 11).

Esta disminución del PPP se refleja en el Estado de Flujos de Efectivo para el año 2016 con una salida de caja de 4.7 millones por adeudo a proveedores dando como resultado que los flujos de efectivo por actividades de operación sean de 1.26 millones. (Anexo 4).

En el año 2017 se incrementa el CCE a 221 días, como consecuencia del incremento del PPC a 78 días y la disminución del PPP con proveedores a 38 días.

La disminución del PPP y el incremento del PPC, se puede apreciar en el Estado de Flujos de Efectivo del año 2017 con una disminución de caja por pago a proveedores de 1.94 millones, de igual manera una disminución de caja de las cuentas por cobrar 
clientes de 2.19 dando como resultado flujos de efectivo por actividades de operación de 1.46 millones.

Figura 4. 4

Razones de Gestión

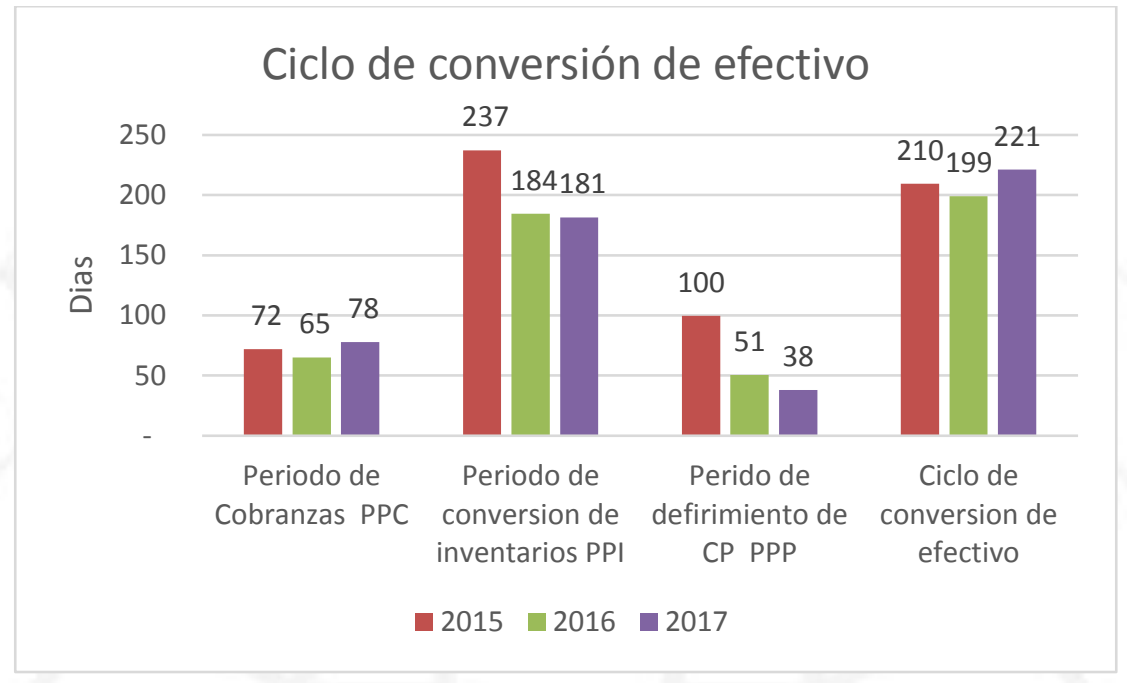

Fuente: Bolsa de valores (2017)

Elaboración propia

\subsubsection{Razón de solvencia}

La empresa Manufactura de Metales y Aluminio Record S.A. alcanzó en el año 2016 el menor nivel de deuda, así la razón de deuda (Total Pasivos/Total de Activos) fue de 31 $\%$; de la misma manera, la razón deuda financiera (Deuda Corto Plazo + Deuda Largo Plazo/Total Activos) alcanzó un nivel de 7 \% y la cobertura de intereses (Ebit/Gastos Financieros) fue de 4.08 veces y los bancos exigen mayor a tres veces.

Según el Estado de Flujos de Efectivo del año 2016, se amortizó deuda por un millón de soles, el cual hizo disminuir el nivel deuda.

En el año 2017, aumenta su razón de deuda a 36, razón de deuda financiera a 10\% y la cobertura de intereses disminuye a 2.01 veces elevando su nivel de riesgo financiero. El Estado de Flujos de Efectivo para el año 2017 señala un incremento de la deuda de corto plazo y de largo plazo por 3.77 y 1.51 millones de soles para el pago de dividendos y recompra de acciones de inversión. 
Figura 4.5

Razones de Solvencia

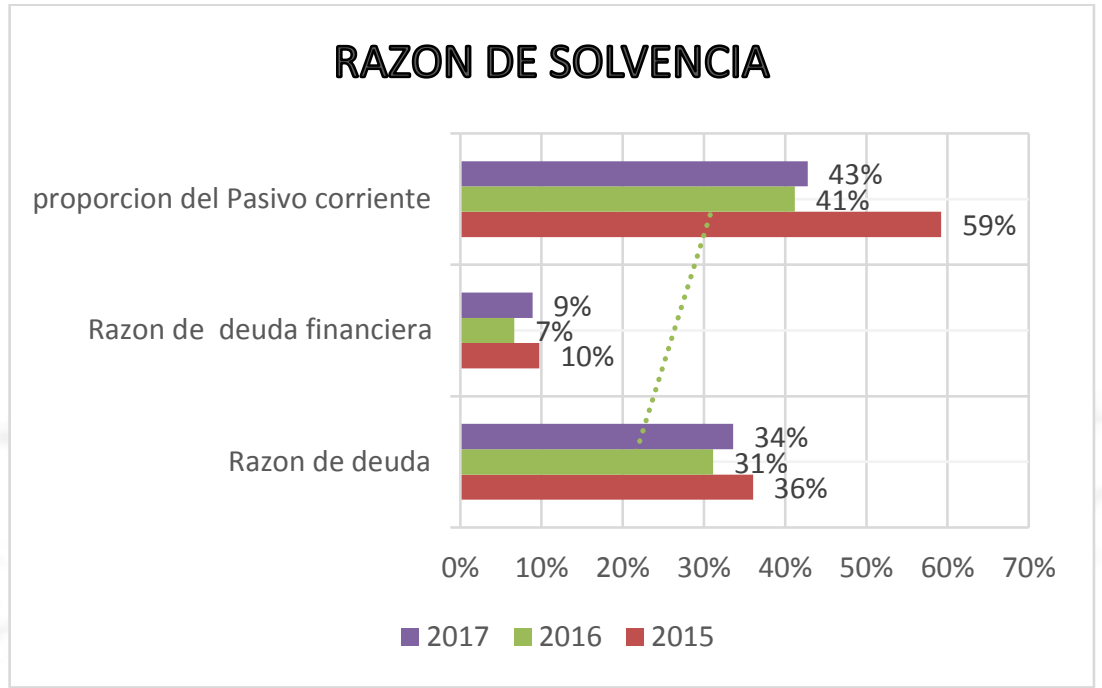

Fuente: Bolsa de valores (2017)

Elaboración propia

Figura 4. 6

Razón de Solvencia. Cobertura de Intereses

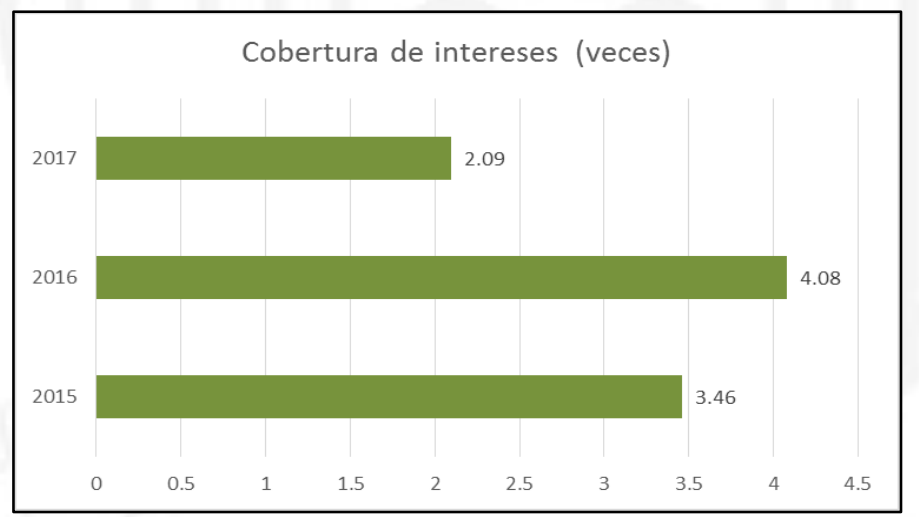

Fuente: Bolsa de valores (2017)

Elaboración propia

\subsubsection{Razón de rentabilidad}

Manufactura de Metales y Aluminio Record S.A. presenta niveles bajos de margen neto como consecuencia de los gastos administrativos y gastos de ventas que representan en promedio el $11 \%$ y $25.1 \%$ respectivamente (ver Anexo 2). 
En el año 2016, la empresa alcanzó un margen neto de $1.29 \%$ por el crecimiento de las ventas de $16.1 \%$, por lo tanto, se obtuvo el mayor ROA y ROE y fue de $0.87 \%$ y $1.26 \%$ respectivamente, la diferencia se debe según el método Dupont al multiplicador del patrimonio que fue de 1.45 .

En el año 2017, el margen neto fue de $0.3 \%$ por la disminución de las ventas de $5.6 \%$ obteniéndose un ROA y ROE de $0.14 \%$ y $0.21 \%$ respectivamente.

\section{Figura 4.7}

Margen Bruto, operativo y neto

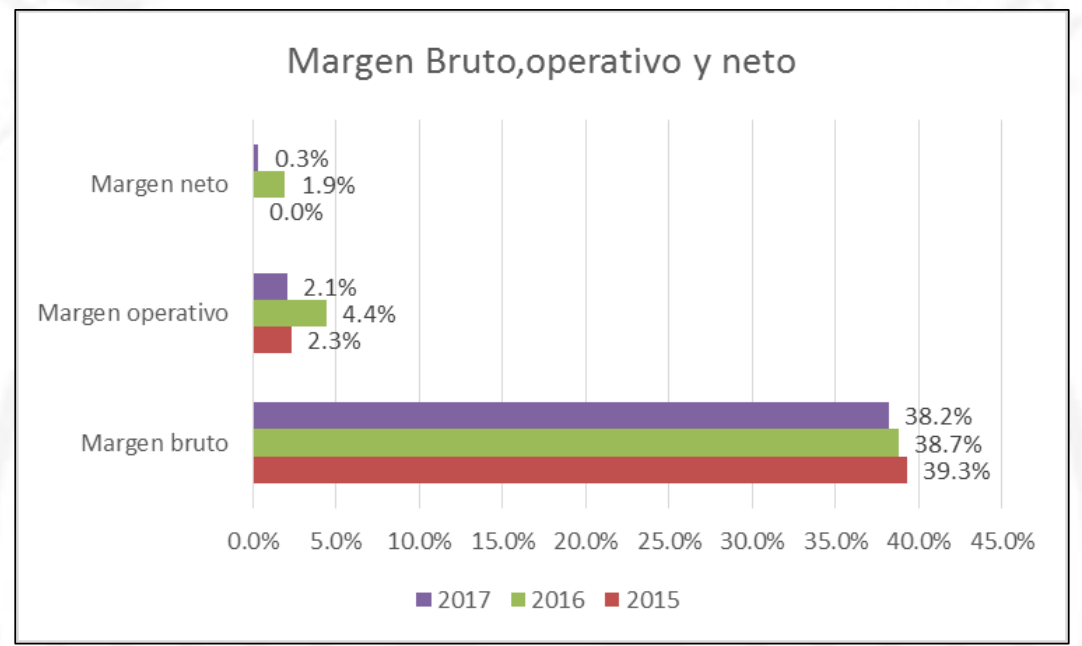

Fuente: Bolsa de valores (2017)

Elaboración propia

Figura 4.8

Método Dupont

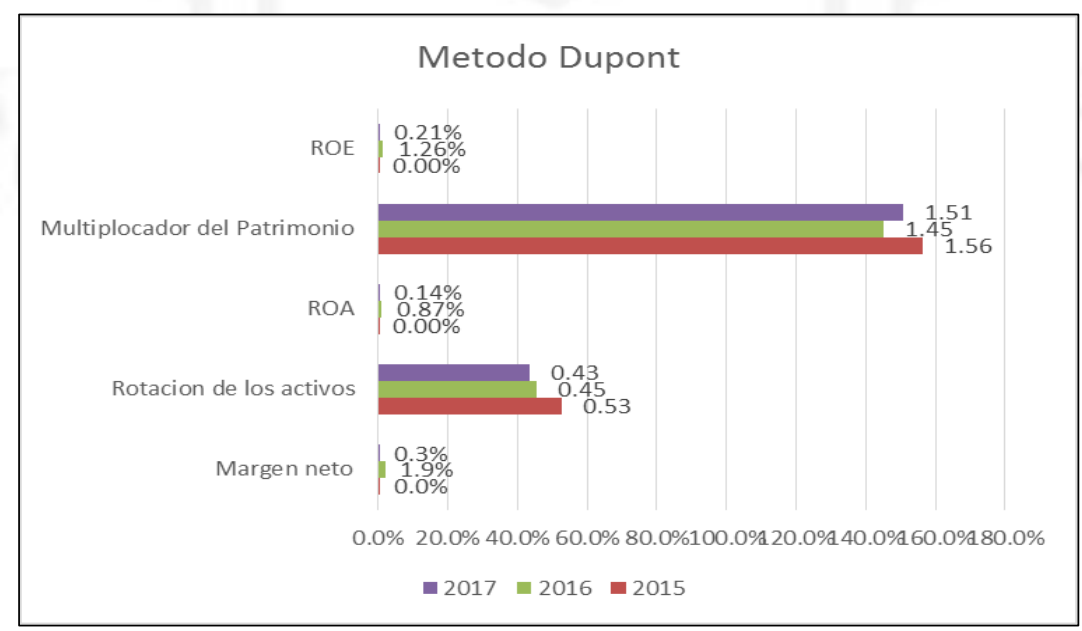

Fuente: Bolsa de valores (2017) 


\subsubsection{Razón de mercado}

El Precio de Mercado de Manufactura de Metales y Aluminio Record S.A. tiene una baja frecuencia de negociación; es decir, no pasa el nivel de $5 \%$ por lo tanto, no es una buena referencia para los cálculos realizados.

La utilidad por acción de la empresa (UPA) en términos anuales alcanzó su máximo valor de 0.0468 soles por acción (Margen Neto casi 0\%) en el año 2016. Lo que llevo a alcanzar un PER (Precio/UPA) de 21 el cual nos dice que en 21 años estaríamos recuperando nuestra inversión; es un PER muy alto; por lo tanto, es una señal de venta (ver Anexo 5).

En cambio, el ratio Precio/vca (precio/valor contable por acción) está por debajo del precio de cotización lo que significa que el valor contable por acción es de 3.46 soles y el precio de mercado es de 0.91 (si se liquidara la empresa al menos recibiría el valor contable); por lo tanto, es una señal de compra.

Para el año 2017, hay una clara señal de venta en términos de PER es de 134x y su Precio/vca es de $0.25 x$ el cual es una señal de compra.

Figura 4. 9

Ratios de Mercado

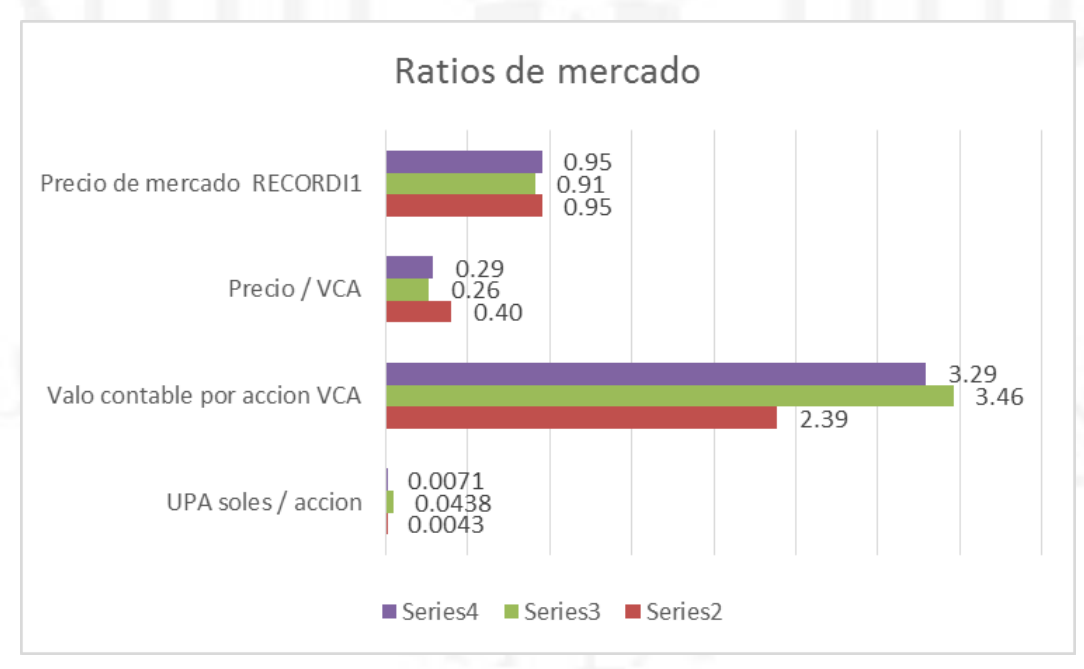

Fuente: Bolsa de valores (2017)

Elaboración propia 
Figura 4. 10

Estructura de los Gastos de Ventas

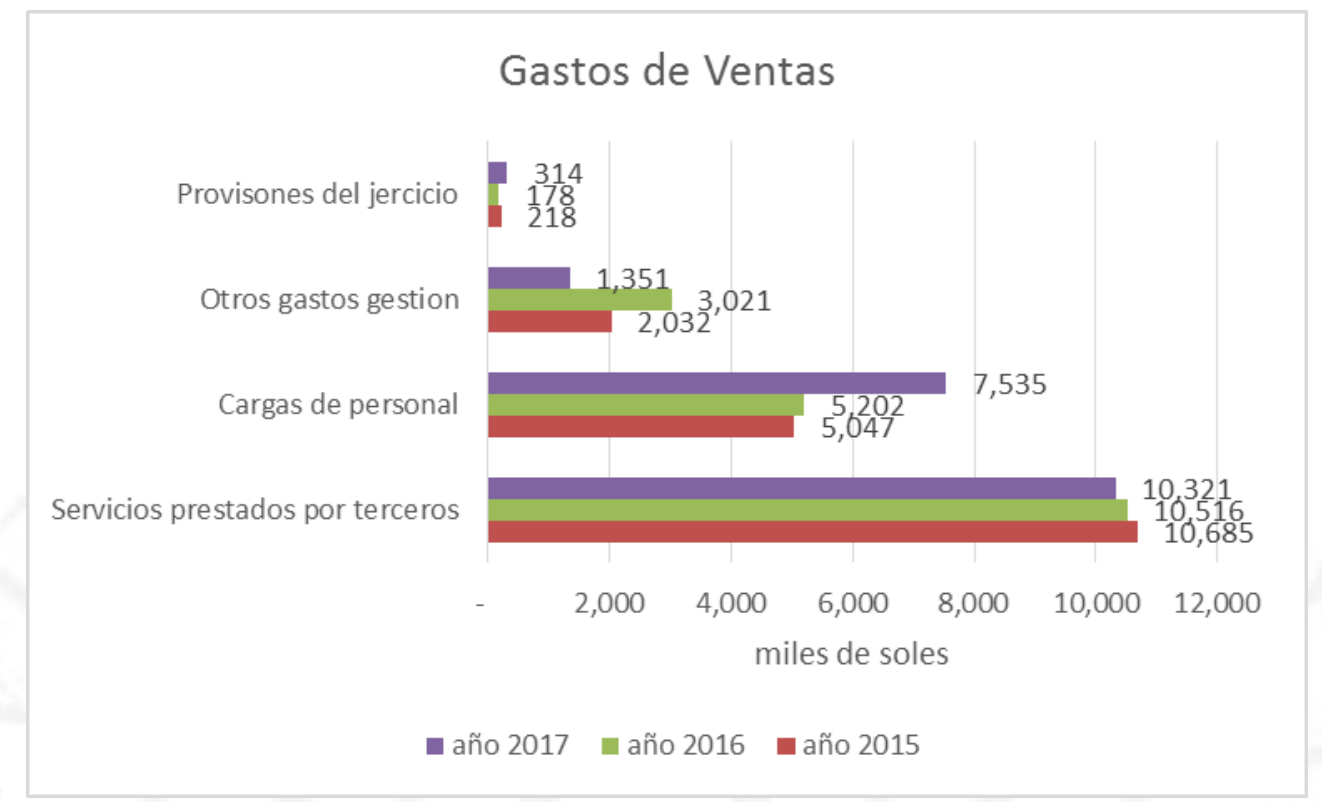

Fuente: Bolsa de valores (2017)

Elaboración propia

\subsubsection{Supuestos de la proyección de los Estados Financieros periodo 2018 - 2022}

1. Para proyectar las ventas se tomó un promedio aritmético del crecimiento de las ventas de los últimos dos años dando un peso de $60 \%$ al crecimiento de las ventas del año 2017 y un $40 \%$ pata el año 2016 con el objetivo de marcar tendencia. Tasa de crecimiento de las ventas es $3.07 \%$. Asimismo, se tomó en cuenta el crecimiento anual del PBI del Sector Económico y el crecimiento anual de las exportaciones. Dichos datos fueron escogidos de las Proyecciones Económicas Multianuales (2018 al 2020) que fueron aprobadas el 23 de agosto del 2017.

El crecimiento anual proyectado del PBI se definió en base a tres etapas: la primera etapa que se da en el año 2017 ya que inicia el crecimiento acelerado de la economía peruana debido al proceso de reconstrucción y a los trabajos de infraestructura como Línea 2 de metro de Lima, Gaseoducto Sur, etc. La segunda etapa inicia en el 2018 se percibe una mejora sosegada de la inversión privada en consecuencia de una mayor demanda interna, el 
incremento de los precios de los metales y el desarrollo de importantes proyectos de infraestructura. La tercera etapa que va desde el 2019 hasta el 2022 se estima que la tasa de crecimiento se consolidará en un $4 \%$ debido al aumento de la inversión en infraestructura, en el sector de hidrocarburos y minero.

Finalmente, el crecimiento de las exportaciones se estima que crecerá a un ritmo de $3.18 \%$ en el sector construcción.

2. El Costo de Ventas se proyectará en base al análisis realizado en el Ratio de Margen Bruto de los años 2015 al 2017 dando un promedio de 38.5\%. Por consiguiente, dicho porcentaje de Margen Bruto se utilizará como base para las proyecciones del costo de ventas de los años 2018-2022.

1. La estructura de costos del Estado de Resultados es un promedio aritmético de los últimos 2 años.

2. Para proyectar el Estado de Situación Financiera se ha tomado la proyección del crecimiento de las ventas.

3. Los activos fijos crecen a una tasa de $0.5 \%$ de acuerdo a su comportamiento histórico.

4. La empresa no tomara nuevos préstamos a corto plazo para los próximos 5 años con el fin de bajar su nivel de deuda.

5. El capital accionario crecerá a la tasa de las ventas para financiar parte del capex (gasto de capital) y mejorar su nivel de deuda.

6. Para proyectar los gastos financieros se ha calculado la tasa de interés dividiendo los gastos financieros entre la deuda financiera de corto y largo plazo.

7. Se asume un impuesto a la renta de $29.5 \%$.

8. Se ha proyectado los 4 estados financieros: Estado de Situación Financiera, Estado de Resultados, Estado de Flujos de Efectivo y Estado de Cambios en el Patrimonio Neto de acuerdo a la NIC 01 (Presentación de Estados Financieros). 


\subsubsection{Impacto de las NIIF en la Proyección de los Estados Financieros}

Manufactura de Metales y Aluminio Record S.A. (en adelante la Compañía), ha estado expectante de la entrada en vigencia de las nuevas normas contables que pretenden presentar los estados financieros de forma más razonable y fiable a la realidad económica de la Compañía en relación a sus operación y expectativas financieras. Las nuevas normas financieras que serán materia de análisis e impacto en las proyecciones financieras de la Compañía son:

- La NIIF 15, Ingresos de actividades ordinarias procedentes de contratos con clientes, esta norma reemplaza a la NIC 18 Ingresos de actividades ordinarias, la NIC 11 Contratos de construcción y a las interpretaciones correspondientes. La nueva norma desarrolla un único criterio para el reconocimiento de los ingresos, bajo el concepto de transferencia de control que reemplaza la noción existente de riesgos y beneficios. Cuya vigencia obligatoria es a partir del 1 de enero de 2018.

- La NIIF 9, Instrumentos financieros, reemplaza la NIC 39. Esta nueva norma mantiene, pero simplifica, el modelo mixto de medición de los instrumentos financieros de la NIC 39 y establece tres categorías principales de medición para los activos financieros. Asimismo, modifica los criterios para el reconocimiento de pérdidas por deterioro de activos financieros, en función de un modelo que se basa en estimar la pérdida esperada de la cartera de créditos que reemplazará el modelo actual con base en el concepto de 'pérdidas incurridas'. También modifica las condiciones que una entidad debe cumplir para aplicar contabilidad de cobertura. Cuya vigencia obligatoria es a partir del 1 de enero de 2018.

- La NIIF 16, Arrendamientos que reemplazará la NIC 17, Arrendamientos y a la CINIIF 4, 'Contratos que podrían contener un arrendamiento' y otras interpretaciones relacionadas. Esta nueva norma, impactará sustancialmente a los arrendatarios, debido que resultará en el reconocimiento de casi todos sus arrendamientos en el estado de situación financiera. La norma elimina, para el arrendatario, la distinción entre el arrendamiento operativo y financiero y 
requiere el reconocimiento de un activo que representa su derecho de uso del bien arrendado y una deuda financiera por la obligación de efectuar los pagos futuros contractuales, con excepción de contratos con plazo de duración menor a 12 meses y contratos de arrendamientos de bienes menores. Cuya vigencia obligatoria es a partir del 1 de enero de 2019.

Las normas previamente resumidas, son aquéllas que la Compañía, en función de su complejidad y relación con sus operaciones, se esperan cierto impacto en la fase inicial de identificación de diferencias conceptuales entre las nuevas normas y las normas actuales y la implementación de las mismas. Dichos impactos en las proyecciones de los estados financieros serán revisados y analizados en el presente trabajo de investigación.

La Norma Internacional de Información Financiera 9 (NIIF 9) impone un nuevo análisis sobre la contabilidad de cobertura, medición y clasificación de instrumentos financieros y deterioro de los activos y pasivos financieros. En el caso de la Compañía el mayor impacto que podría afectar los flujos y resultados futuros está por el cálculo y efecto de la implementación del deterioro de los activos financieros (cuentas por cobrar comerciales) bajo el modelo simplificado, este cambio corresponde a la medición en el cálculo de las provisiones que actualmente solo se basa en un anticuamiento en relación al vencimiento de dichas cuentas, los cambios corresponden es realizar un análisis de la pérdida histórica por tipo de segmentos de clientes bajo el mismo riesgo y adicionarle el efecto de las perspectivas del comportamiento macroeconómico del contexto donde realiza sus operaciones la Compañía (efecto Forward Looking). Dado que anteriormente la compañía manejaba su provisión de cobranza dudosa bajo un anticuamiento sobre el vencimiento de los activos financieros no consideraba la realidad de las pérdidas reales de cada segmento de clientes. Es por esto que los cambios requeridos por la NIIF 9 recoge estos efectos y considera provisiones por tramos, dicho esto la compañía se podría ver afectada en los resultados del periodo en caso la política anterior no refleje correctamente el comportamiento de riesgo de crédito de la Compañía. En consecuencia, los resultados de la compañía se podrían ver afectar por las nuevas provisiones por deterioro de la cartera bajo los requerimientos de la NIIF 9 y por consecuencia reducir los flujos proyectados de los mismos.

Por otro lado, el impacto que se espera en la Compañía por la implementación de NIIF 16 es bajo, debido a que la compañía en la actualidad no maneja muchos contratos 
de arrendamiento operativo. Los mayores impactos que se esperarían que pudieran afectar las proyecciones por los efectos de la implementación de la NIIF 16 son:

- Mayor pasivo por arrendamiento, afectando los ratios de endeudamiento.

- Reducción en los ratios de rentabilidad de los activos.

- Aumento del EBITDA.

- Aumento del resultado operativo.

- Reducción de los cargos por intereses.

- Aumento en el flujo de operación.

- Reducción en el flujo de financiamiento.

Mencionado los posibles efectos, no se espera impacto en las proyecciones (en balance ni en resultados) dado que la compañía actualmente no maneja arrendamientos operativos significativos. En caso en periodos futuros se firmen contratos nuevos de arrendamiento los impactos serían los mencionados anteriormente.

En resumen, no se espera impacto significativo por las dos normas descritas anteriormente en el flujo operativo y proyecciones de la compañía debido a que la Compañía tiene controlado los efectos de riesgo de crédito y cuenta con amplio capital para adquirir sus propias flotas, equipos e instalaciones. 
Tabla 4. 2

Proyección del Estado de Situación Financiera Periodo 2018 - 2022

\begin{tabular}{|c|c|c|c|c|c|c|c|c|c|c|c|}
\hline \multicolumn{11}{|c|}{ Estado Financiero Anual Individual del Año 2016 (En miles de nuevos soles) } & \\
\hline ESTADO DE SITUACION FINANCIEI & 2015 & 2016 & 2017 & $2018 \mathrm{P}$ & 2019 P & $2020 P$ & $2021 P$ & $2022 \mathrm{P}$ & 2015 & 2016 & 2017 \\
\hline \multicolumn{12}{|l|}{ Activos/ } \\
\hline \multicolumn{12}{|l|}{ Activos Corrientes/ } \\
\hline Efectivo y Equivalentes al Efectivo, & 807 & 1,056 & 699 & 1,220 & 1,788 & 2,405 & 3,073 & 3,793 & $0.6 \%$ & $0.6 \%$ & $0.4 \%$ \\
\hline |Cuentas por Cobrar Comerciales/ & 16,326 & 17,115 & 19,304 & 19,897 & 20,508 & 21,137 & 21,786 & 22,455 & $12.4 \%$ & $9.7 \%$ & $11.1 \%$ \\
\hline |Otras Cuentas por Cobrar/ & 1,869 & 1,285 & 1,806 & 1,861 & 1,919 & 1,978 & 2,038 & 2,101 & $1.4 \%$ & $0.7 \%$ & $1.0 \%$ \\
\hline |Inventarios/ & 27,634 & 25,176 & 23,583 & 24,307 & 25,054 & 25,823 & 26,616 & 27,433 & $21.0 \%$ & $14.2 \%$ & $13.5 \%$ \\
\hline \multicolumn{3}{|l|}{ Activos por Impuestos a las Ganancias/ } & 356 & 367 & 378 & 390 & 402 & 414 & $0.0 \%$ & $0.0 \%$ & $0.2 \%$ \\
\hline |Otros Activos no Financieros/ & 479 & 705 & 237 & 244 & 252 & 260 & 267 & 276 & $0.4 \%$ & $0.4 \%$ & $0.1 \%$ \\
\hline Total Activos Corrientes/ & 47,115 & 45,337 & 45,985 & 47,897 & 49,898 & 51,993 & 54,183 & 56,473 & $35.9 \%$ & $25.6 \%$ & $26.3 \%$ \\
\hline \multicolumn{12}{|l|}{ Activos No Corrientes/ } \\
\hline Propiedades, Planta y Equipo/ & 84,205 & 131,183 & 128,698 & 129,341 & 129,988 & 130,638 & 131,291 & 131,948 & $64.1 \%$ & $74.1 \%$ & $73.7 \%$ \\
\hline Activos por Impuestos Diferidos/ & 96 & 479 & & 0 & 0 & 0 & 0 & 0 & $0.1 \%$ & $0.3 \%$ & $0.0 \%$ \\
\hline Total Activos No Corrientes/ & 84,301 & 131,662 & 128,698 & 129,341 & 129,988 & 130,638 & 131,291 & 131,948 & $64.1 \%$ & $74.4 \%$ & $73.7 \%$ \\
\hline TOTAL ACTIVOS/ & 131,416 & 176,999 & 174,683 & 177,238 & 179,886 & 182,631 & 185,474 & 188,420 & $100.0 \%$ & $100.0 \%$ & $100.0 \%$ \\
\hline \multicolumn{12}{|l|}{ Pasivos y Patrimonio/ } \\
\hline \multicolumn{12}{|l|}{ Pasivos Corrientes/ } \\
\hline Otros Pasivos Financieros/ & 12,796 & 11,797 & 15,571 & 15,571 & 15,571 & 15,571 & 15,571 & 15,571 & $9.7 \%$ & $6.7 \%$ & $8.9 \%$ \\
\hline |Cuentas por Pagar Comerciales/ & 11,608 & 6,893 & 4,952 & 5,104 & 5,261 & 5,422 & 5,589 & 5,760 & $8.8 \%$ & $3.9 \%$ & $2.8 \%$ \\
\hline Otras cuentas por pagar & 3,649 & 4,013 & 4,587 & 4,728 & 4,873 & 5,023 & 5,177 & 5,336 & $2.8 \%$ & $2.3 \%$ & $2.6 \%$ \\
\hline |Total Pasivos Corrientes/ & 28,053 & 22,703 & 25,110 & 25,403 & 25,705 & 26,016 & 26,337 & 26,667 & $21.3 \%$ & $12.8 \%$ & $14.4 \%$ \\
\hline \multicolumn{12}{|l|}{ Pasivos No Corrientes/ } \\
\hline Otros Pasivos Financieros/ & & & 1,507 & 1,553 & 1,601 & 1,650 & 1,701 & 1,753 & $0.0 \%$ & $0.0 \%$ & $0.9 \%$ \\
\hline Pasivos por Impuestos Diferidos/ & 19,307 & 32,393 & 32,087 & 32,087 & 32,087 & 32,087 & 32,087 & 32,087 & $14.7 \%$ & $18.3 \%$ & $18.4 \%$ \\
\hline Total Pasivos No Corrientes/ & 19,307 & 32,393 & 33,594 & 33,640 & 33,688 & 33,737 & 33,788 & 33,840 & $14.7 \%$ & $18.3 \%$ & $19.2 \%$ \\
\hline Total Pasivos/ & 47,360 & 55,096 & 58,704 & 59,043 & 59,393 & 59,753 & 60,124 & 60,507 & $36.0 \%$ & $31.1 \%$ & $33.6 \%$ \\
\hline \multicolumn{12}{|l|}{ Patrimonio/ } \\
\hline Capital Emitido/ & 25,630 & 25,630 & 25,630 & 26,417 & 27,228 & 28,064 & 28,926 & 29,814 & $19.5 \%$ & $14.5 \%$ & $14.7 \%$ \\
\hline |Primas de Emisión/ & & & 249 & 257 & 265 & 273 & 281 & 290 & & & \\
\hline Acciones de Inversión/ & 9,602 & 9,602 & 9,602 & 9,897 & 10,201 & 10,514 & 10,837 & 11,170 & $7.3 \%$ & $5.4 \%$ & $5.5 \%$ \\
\hline Acciones Propias en Cartera/ & & & $-4,974$ & $-4,974$ & $-4,974$ & $-4,974$ & $-4,974$ & $-4,974$ & & & \\
\hline |Otras Reservas de Capital/ & 1,399 & 1,399 & 1,553 & 1,553 & 1,553 & 1,553 & 1,553 & 1,553 & $1.1 \%$ & $0.8 \%$ & $0.9 \%$ \\
\hline |Resultados Acumulados/ & 47,425 & 50,647 & 49,294 & 50,420 & 51,596 & 52,823 & 54,102 & 55,435 & $36.1 \%$ & $28.6 \%$ & $28.2 \%$ \\
\hline |Otras Reservas de Patrimonio/ & 0 & 34,625 & 34,625 & 34,625 & 34,625 & 34,625 & 34,625 & 34,625 & $0.0 \%$ & $19.6 \%$ & $19.8 \%$ \\
\hline Total Patrimonio/ & 84,056 & 121,903 & 115,979 & 118,195 & 120,494 & 122,878 & 125,349 & 127,912 & $64.0 \%$ & $68.9 \%$ & $66.4 \%$ \\
\hline TOTAL PASIVOS Y PATRIMONIO/ & 131,416 & 176,999 & 174,683 & 177,238 & 179,886 & 182,631 & 185,474 & 188,419 & $100.0 \%$ & $100.0 \%$ & $100.0 \%$ \\
\hline Fuente : BVL & 0 & 0 & 0 & 0 & 0 & 0 & 0 & 1 & & & \\
\hline
\end{tabular}

Fuente: Supertintendecia de Mercado de Valores. (s.f.a)

Elaboración propia 
Tabla 4.3

Proyección del Estado de Resultados del Periodo 2018 - 2022

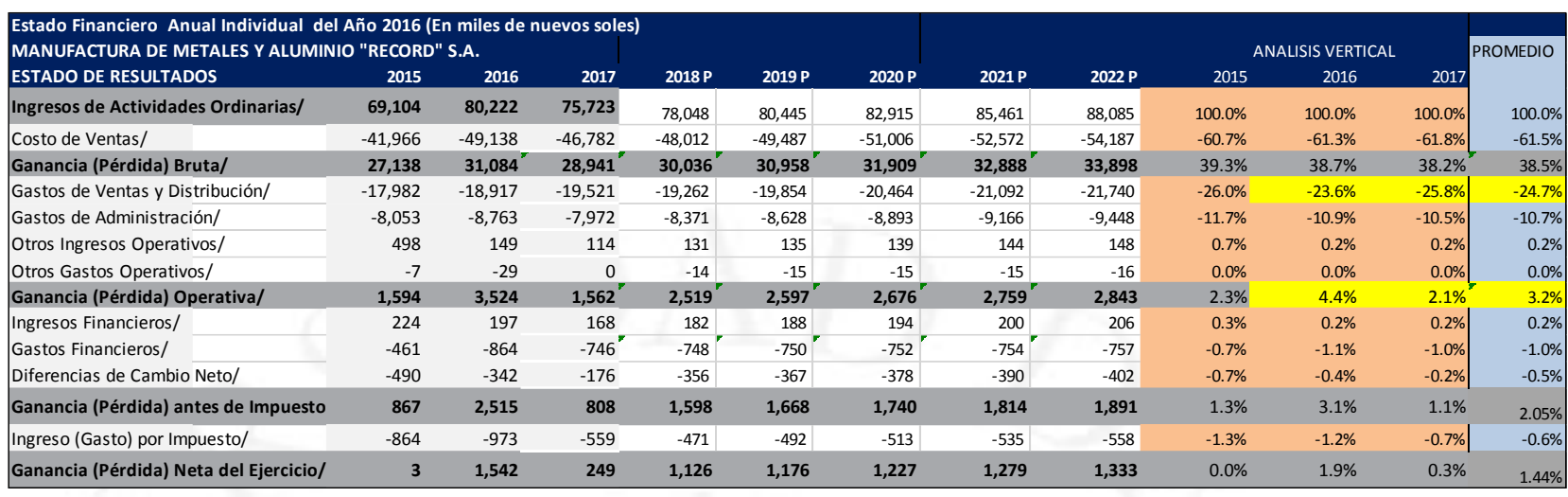

Fuente: Supertintendecia de Mercado de Valores. (s.f.b)

Elaboración propia

Tabla 4.4

Proyección del Estado de Cambios en el Patrimonio Neto periodo 2018 - 2022

\begin{tabular}{|c|c|c|c|c|c|c|c|}
\hline \multicolumn{8}{|c|}{$\begin{array}{l}\text { Manufactura RECORD CAMBIO PATRIMONIAL } \\
\text { RECONCILIACION DEL PATRIMONIO (en miles de soles) }\end{array}$} \\
\hline CONCEPTOSI FECHASITE & 2016 & 2017 & 2018 P & 2019 P & $2020 P$ & $2021 \mathrm{P}$ & $2022 \mathrm{P}$ \\
\hline Patrimonio Neto Inicial: & 84,056 & 121,903 & 115,979 & 118,195 & 120,494 & 122,878 & 125,349 \\
\hline Utilidad/(Pérdida) Neta & 1,542 & 249 & 1,126 & 1,176 & 1,227 & 1,279 & 1,333 \\
\hline \multicolumn{8}{|l|}{ Acciones de inversion } \\
\hline \multicolumn{8}{|l|}{ Ajuste Patrimonial } \\
\hline Aportes de Capital & & & 1,089 & 1,123 & 1,157 & 1,193 & 1,230 \\
\hline Revaluación de inmuebles y equipo & 49,113 & & & & & & \\
\hline Dividendos/Utilidades entregadas & & $(1,388)$ & & & & & \\
\hline \multicolumn{8}{|l|}{ Ganancias por instrumentos derivados financieros } \\
\hline \multicolumn{2}{|l|}{ Compra de acciones de inversion } & $(4,725)$ & & & & & \\
\hline \multicolumn{2}{|l|}{ Impuesto a la Renta Diferido } & & & & & & \\
\hline \multicolumn{8}{|l|}{ Otras Deducciones (otro resultado integral) } \\
\hline Ajustes & (7) & (60) & & & 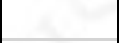 & & \\
\hline Patrimonio Neto Final: & 121,903 & 115,979 & 118,195 & 120,494 & 122,878 & 125,349 & 127,912 \\
\hline Cambio Neto Patrimonial: & 37,847 & $(5,924)$ & 2,216 & 2,299 & 2,384 & 2,472 & 2,563 \\
\hline \multirow[t]{2}{*}{ VERIFICACION CUADRE DE RECONCILIACION } & 37,847 & $(5,924)$ & 2,216 & 2,299 & 2,384 & 2,472 & 2,563 \\
\hline & & & - & - & - & - & - \\
\hline
\end{tabular}

Fuente: Supertintendecia de Mercado de Valores. (s.f.b)

Elaboración propia 
Tabla 4. 5

Proyección del Estado de Flujos de Efectivo Periodo 2018 - 2022

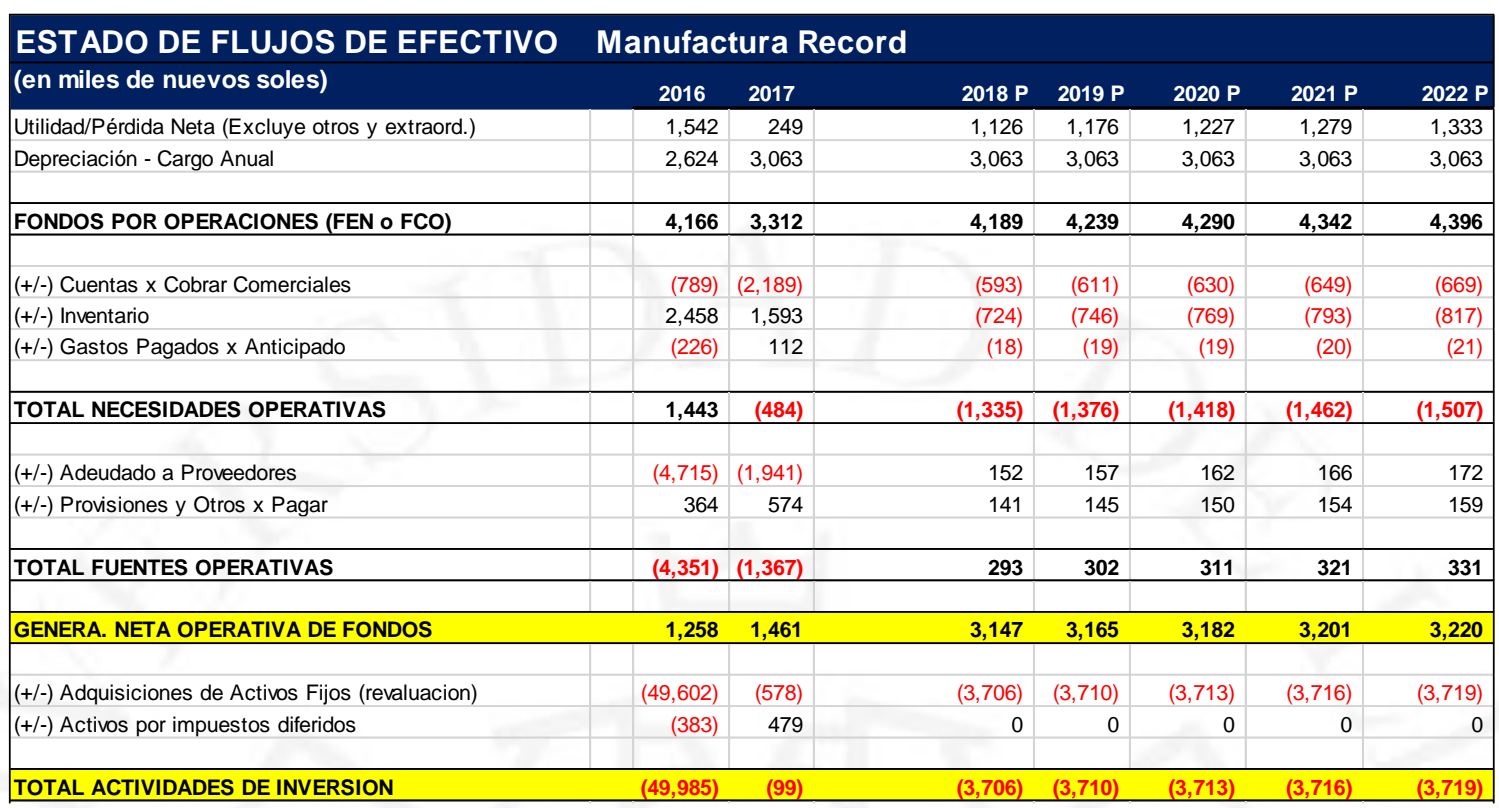

(Continúa)

(Continuación)

\begin{tabular}{|c|c|c|c|c|c|c|c|}
\hline Deuda Bancaria a corto Plazo & (999) & 3774 & 0 & 0 & & & \\
\hline & & & & & & & \\
\hline & & & & & & & \\
\hline \multicolumn{8}{|l|}{ Repago Deuda Bancaria a Largo Plazo } \\
\hline Incremento Deuda Bancaria a largo Plazo & 0 & 1,507 & 46 & 48 & 49 & 51 & 52 \\
\hline Pasivos por impuestos diferidos & 13,086 & $(306)$ & 0 & 0 & 0 & 0 & 0 \\
\hline Aportes de Capital & & & 1,089 & 1,123 & 1,157 & 1,193 & 1,230 \\
\hline Dividendos Pagados & & $(1,388)$ & 0 & 0 & 0 & 0 & 0 \\
\hline Compra de acciones de inversion & & $(4,725)$ & 0 & 0 & 0 & 0 & 0 \\
\hline TOTAL ACTIVIDADES FINANCIAMIENTO & 12,087 & $(1,138)$ & 1,136 & 1,171 & 1,207 & 1,244 & 1,283 \\
\hline & & & & & & & \\
\hline$(+/-)$ Otros Activos a Corto (Otras cxc) & 584 & (521) & (55) & (57) & (59) & (61) & (63) \\
\hline Otros Ingresos/Egresos & 36,305 & (60) & 0 & 0 & 0 & 0 & 0 \\
\hline \multicolumn{8}{|l|}{ Ajustes + Otros } \\
\hline TOTAL OTROS ITEMS NO-OPERATIVOS & 36,889 & $(581)$ & $(55)$ & $(57)$ & $(59)$ & (61) & (63) \\
\hline (+/-) CAJA Y VALORES NEGOCIABLES & 249 & (357) & 521 & 568 & 617 & 667 & 721 \\
\hline Caja Inicial & 807 & 1,056 & 699.0 & $1,220.0$ & $1,788.4$ & $2,405.5$ & $3,073.0$ \\
\hline Caja final & 1,056 & 699 & 1,220 & 1,788 & 2,405 & 3,073 & 3,793 \\
\hline
\end{tabular}

Fuente: Supertintendecia de Mercado de Valores. (s.f.b)

Elaboración propia

\subsubsection{Análisis de la proyección de los estados financieros}

La proyección de los estados de los estados financieros tiene como propósito que la empresa Manufactura de Metales y Aluminio Record S.A. pueda tomar decisiones en 
términos de financiamiento e inversión con la finalidad de mejorar la liquidez y rentabilidad.

En un entorno económico mundial de incremento de la tasa de interés por parte de la FED e incremento de aranceles por parte de EE. UU. y China, las empresas de los países emergentes se ven afectados por una disminución de las ventas e incremento de las tasas interés nacional.

Manufactura de Metales y Aluminio Record S.A. tiene márgenes operativos muy bajos: en el año 2016 tuvo un margen operativo de $4.4 \%$ y en el 2017 tuvo un margen operativo de $2.1 \%$. Para la proyección se ha considerado un margen operativo promedio de $3.2 \%$, esto lo podría lograr si los gastos de ventas y distribución los mantiene a niveles del año 2016 donde tuvo un incremento importante de las ventas de $16.1 \%$ (ver Anexo $1)$.

Al mejorar la empresa el margen operativo y la cobertura de intereses mejora como también el ROA y el ROE. De igual manera el PER.

El ciclo de conversión de efectivo (CCE) se mantiene a niveles del año 2017 para sustentar las ventas (ver Anexo 5).

Para mejorar su nivel de liquidez y solvencia para los próximos cinco años Manufactura de Metales y Aluminio Record S.A. debería financiar parte de sus inversiones con incremento del capital social y mantener constante su línea de financiamiento de corto plazo.

Para obtener una mayor Rentabilidad en términos de ROA y ROE, la empresa debería mejorar sus gastos de ventas y distribución llevándolo a niveles del año 2016, principalmente cuando nos referimos a sus puntos de ventas propio. 


\section{CAPÍTULO V. CONCLUSIONES Y RECOMENDACIONES}

\subsection{Conclusiones}

1. El análisis financiero realizado a la empresa Manufactura de Metales y Aluminio Record S.A. demostró la importancia de la misma para la toma de decisiones debido a que permite plantear estrategias que ayuden a maximizar el valor de la empresa y a su vez mejorar la optimización de los procesos. A su vez, se ha podido determinar que el análisis financiero permite desarrollar medidas que permitan amortiguar el impacto de los sucesos que están fuera de control de la empresa.

2. Para el año 2017, la liquidez disminuye debido al aumento de las obligaciones financieras con bancos como consecuencia del incremento de deuda a corto plazo para pagar dividendos y para la recompra de acciones de inversión.

3. Manufactura de Metales y Aluminio Record S.A. al mantener niveles altos de inventarios con la finalidad de atender clientes y ventas promocionales de comienzos de año hace que la prueba acida disminuya menos de la mitad respecto al ratio de liquidez. Asimismo, la empresa aumenta su razón de deuda disminuyendo la cobertura de intereses a dos veces generando consigo un aumento de riesgo financiero.

4. En el año 2017, se incrementa el ciclo de conversión de efectivo (CCE) como consecuencia del incremento del periodo promedio de cobranzas (PPC) y la disminución del periodo promedio de pagos (PPP).

5. Manufactura de Metales y Aluminio Record S.A. presenta niveles bajos de margen neto como consecuencia de tener gastos administrativos y gastos de ventas muy altos. 
6. Según el Método Dupont es tan bajo el margen neto que obtiene la empresa que solo pudo alcanzar en el año 2016 un ROA y ROE de $0.87 \%$ y $1.26 \%$ respectivamente.

7. Manufactura de Metales y Aluminio Record S.A. tiene márgenes operativos muy bajos; es así, que en el año 2016 y 2017 su margen operativo fue de 4.4 $\%$ y $2.1 \%$ respectivamente. Para la proyección se ha considerado un margen operativo promedio de $3.2 \%$, esto lo podría lograr si los gastos de ventas y distribución los mantiene a niveles del año 2016 donde tuvo un incremento importante de las ventas de $16.1 \%$. Al mejorar el margen operativo, la empresa mejora la cobertura de intereses y a su vez mejora el ROA y el ROE y de igual manera el PER.

\subsection{Recomendaciones}

1. Para mejorar su nivel de liquidez y solvencia Manufactura de Metales y Aluminio Record S.A. ante una mayor Deuda que afecta actualmente el Riesgo Financiero por una cobertura de intereses que representa $2 x$ al año 2017, la empresa para los próximos cinco años debería financiar parte de sus inversiones de largo plazo con incremento del capital social y mantener constante su línea de financiamiento de corto plazo con la finalidad de disminuir su riesgo financiero ante un entorno económico interno de posible incremento de tasa de interés como consecuencia del aumento de la tasa de interés de referencia de la reserva federal FED de los Estados Unidos.

2. Para obtener una mayor Rentabilidad en términos de ROA y ROE y mejorar la cobertura de intereses, la Manufactura de Metales y Aluminio Record S.A. debería mejorar la estrategia de ventas en cuanto la fuerza de ventas ya que la carga de personal de ventas se incrementó en $48 \%$ al año 2017 a pesar de que las ventas disminuyeron en este año $-5.8 \%$. 


\section{REFERENCIAS}

Industria Ciesa. (s.f.). Microempresa. Recuperado de Competidor de Record: http://www.ciesaindustria.com/

¿Qué es una cadena de valor? (25 de abril de 2015). Recuperado de Qué aprendemos hoy: http://queaprendemoshoy.com/que-es-la-cadena-de-valor/

Manufactura de Metales y Aluminio Record S. A. (2018). Memoria Anual y Estados Financieros. Lima. Recuperado de http://www.smv.gob.pe/ConsultasP8/temp/1803_\%20Memoria\%20vs\%202.pdf

Manufactura de Metales y Aluminio Record S. A. (Al 30 de junio de 2018 y 31 de diciembre de 2017). Notas de los Estados Financieros. Recuperado de http://www.record.com.pe/web/pdf/2018/2do-Trimestre/Notas-de-los-EstadosFinancieros-del-Segundo-Trimestre-2018.pdf

Manufactura de Metales y Aluminio Record S.A. (s. f.). Recuperado de Nuestra empresa: http://www.record.com.pe/es/empresa.html

Mercado Libre. (s.f.). Ollas Record. Recuperado de https://hogar.mercadolibre.com.pe/cocina/ollas-record

Paginas Amarillas. (s.f.). Utensilios de cocina en Miraflores, Lima, Perú. Recuperado de https://www.paginasamarillas.com.pe/miraflores-lima/servicios/utensilios-decocina

Perez, R. T. (2013). 2013 Manufactura de Metales y Aluminio Record. Recuperado de https://es.scribd.com/doc/229660968/Manufactura-de-Metales-y-AluminioRecord-s-a-2

Renaware. (s.f.). Ventas con representantes. Recuperado de https://renaware.net/productos/juegos-utensilios/

Sodimac. (s.f.). Lavaderos. Recuperado de https://www.sodimac.com.pe/sodimacpe/category/cat11048/Lavaderos-de-AceroInoxidable?sTerm=lavaderos\&sScenario=BRD_lavaderos

Superintendencia del Mercado de Valores. (s.f.). Proyeccion del Estado de Resultados Manufactura de Metales y Aluminio Record S. A. Recuperado de http://www.smv.gob.pe/Frm_InformacionFinancieraPorPeriodo?data=16BF4C8 EF499F678B5AE402C1CFE8FC16710365A6C

Supertintendecia de Mercado de Valores. (s.f.). Estados de Situación Financiera Manufactura de Metales y Aluminio Record S. A. al 31 de diciembre 2018. Recuperado de 
http://www.smv.gob.pe/Frm_InformacionFinancieraPorPeriodo?data=16BF4C8 EF499F678B5AE402C1CFE8FC16710365A6C

Teka. (s.f.). Lavaderos. Recuperado de Competidor de Record:

http://www.tekaindustrial.com/pe/products/index/15-lavaderos

Tramontina. (2017). Utilidades domésticas. Recuperado de http://www.tramontina.com.pe/empresa/historia 


\section{BIBLIOGRAFÍA}

Traiding Economics. (2017). Steel. Recuperado de http://www.tradingeconomics.com/commodity/steel

Ministerio de Economía y Finanzas - MEF. (2017). Marco Macroeconómico Multianual 2018-2021. Lima: Ministerio de Economía y Finanzas - MEF.

La Moderna. (s.f.). Microempresa. Recuperado de Competidor de Record:

http://www.lamoderna-peru.com/que-hacemos

VIABCP. (2017). Comisones y Tasas. Recuperado de

https://ww3.viabcp.com/tasasytarifas/tarifas.aspx?ASEC=2 
ANEXOS 


\section{Anexo 1: Proyección del Estado de Situación Financiera}

\section{periodo 2018-2022}

\begin{tabular}{|c|c|c|c|c|c|c|c|c|c|c|c|}
\hline \multicolumn{12}{|c|}{ Estado Financiero Anual Individual del Año 2016 (En miles de nuevos soles) } \\
\hline ESTADO DE SITUACION FINANCIEI & 2015 & 2016 & 2017 & $2018 P$ & $2019 \mathrm{P}$ & $2020 \mathrm{P}$ & $2021 \mathrm{P}$ & $2022 \mathrm{P}$ & 2015 & 2016 & 2017 \\
\hline \multicolumn{12}{|l|}{ Activos/ } \\
\hline \multicolumn{12}{|l|}{ Activos Corrientes/ } \\
\hline Efectivo y Equivalentes al Efectivo, & 807 & 1,056 & 699 & 1,220 & 1,788 & 2,405 & 3,073 & 3,793 & $0.6 \%$ & $0.6 \%$ & $0.4 \%$ \\
\hline |Cuentas por Cobrar Comerciales/ & 16,326 & 17,115 & 19,304 & 19,897 & 20,508 & 21,137 & 21,786 & 22,455 & $12.4 \%$ & $9.7 \%$ & $11.1 \%$ \\
\hline Otras Cuentas por Cobrar/ & 1,869 & 1,285 & 1,806 & 1,861 & 1,919 & 1,978 & 2,038 & 2,101 & $1.4 \%$ & $0.7 \%$ & $1.0 \%$ \\
\hline |Inventarios/ & 27,634 & 25,176 & 23,583 & 24,307 & 25,054 & 25,823 & 26,616 & 27,433 & $21.0 \%$ & $14.2 \%$ & $13.5 \%$ \\
\hline \multicolumn{3}{|l|}{ |Activos por Impuestos a las Ganancias/ } & 356 & 367 & 378 & 390 & 402 & 414 & $0.0 \%$ & $0.0 \%$ & $0.2 \%$ \\
\hline |Otros Activos no Financieros/ & 479 & 705 & 237 & 244 & 252 & 260 & 267 & 276 & $0.4 \%$ & $0.4 \%$ & $0.1 \%$ \\
\hline |Total Activos Corrientes/ & 47,115 & 45,337 & 45,985 & 47,897 & 49,898 & 51,993 & 54,183 & 56,473 & $35.9 \%$ & $25.6 \%$ & $26.3 \%$ \\
\hline \multicolumn{12}{|l|}{ Activos No Corrientes/ } \\
\hline Propiedades, Planta y Equipo/ & 84,205 & 131,183 & 128,698 & 129,341 & 129,988 & 130,638 & 131,291 & 131,948 & $64.1 \%$ & $74.1 \%$ & $73.7 \%$ \\
\hline |Activos por Impuestos Diferidos/ & 96 & 479 & & 0 & 0 & 0 & 0 & 0 & $0.1 \%$ & $0.3 \%$ & $0.0 \%$ \\
\hline |Total Activos No Corrientes/ & 84,301 & 131,662 & 128,698 & 129,341 & 129,988 & 130,638 & 131,291 & 131,948 & $64.1 \%$ & $74.4 \%$ & $73.7 \%$ \\
\hline TOTAL ACTIVOS/ & 131,416 & 176,999 & 174,683 & 177,238 & 179,886 & 182,631 & 185,474 & 188,420 & $100.0 \%$ & $100.0 \%$ & $100.0 \%$ \\
\hline \multicolumn{12}{|l|}{ Pasivos y Patrimonio/ } \\
\hline \multicolumn{12}{|l|}{ Pasivos Corrientes/ } \\
\hline |Otros Pasivos Financieros/ & 12,796 & 11,797 & 15,571 & 15,571 & 15,571 & 15,571 & 15,571 & 15,571 & $9.7 \%$ & $6.7 \%$ & $8.9 \%$ \\
\hline |Cuentas por Pagar Comerciales/ & 11,608 & 6,893 & 4,952 & 5,104 & 5,261 & 5,422 & 5,589 & 5,760 & $8.8 \%$ & $3.9 \%$ & $2.8 \%$ \\
\hline Otras cuentas por pagar & 3,649 & 4,013 & 4,587 & 4,728 & 4,873 & 5,023 & 5,177 & 5,336 & $2.8 \%$ & $2.3 \%$ & $2.6 \%$ \\
\hline |Total Pasivos Corrientes/ & 28,053 & 22,703 & 25,110 & 25,403 & 25,705 & 26,016 & 26,337 & 26,667 & $21.3 \%$ & $12.8 \%$ & $14.4 \%$ \\
\hline \multicolumn{12}{|l|}{ Pasivos No Corrientes/ } \\
\hline Otros Pasivos Financieros/ & & & 1,507 & 1,553 & 1,601 & 1,650 & 1,701 & 1,753 & $0.0 \%$ & $0.0 \%$ & $0.9 \%$ \\
\hline Pasivos por Impuestos Diferidos/ & 19,307 & 32,393 & 32,087 & 32,087 & 32,087 & 32,087 & 32,087 & 32,087 & $14.7 \%$ & $18.3 \%$ & $18.4 \%$ \\
\hline |Total Pasivos No Corrientes/ & 19,307 & 32,393 & 33,594 & 33,640 & 33,688 & 33,737 & 33,788 & 33,840 & $14.7 \%$ & $18.3 \%$ & $19.2 \%$ \\
\hline Total Pasivos/ & 47,360 & 55,096 & 58,704 & 59,043 & 59,393 & 59,753 & 60,124 & 60,507 & $36.0 \%$ & $31.1 \%$ & $33.6 \%$ \\
\hline \multicolumn{12}{|l|}{ Patrimonio/ } \\
\hline Capital Emitido/ & 25,630 & 25,630 & 25,630 & 26,417 & 27,228 & 28,064 & 28,926 & 29,814 & $19.5 \%$ & $14.5 \%$ & $14.7 \%$ \\
\hline |Primas de Emisión/ & & & 249 & 257 & 265 & 273 & 281 & 290 & & & \\
\hline |Acciones de Inversión/ & 9,602 & 9,602 & 9,602 & 9,897 & 10,201 & 10,514 & 10,837 & 11,170 & $7.3 \%$ & $5.4 \%$ & $5.5 \%$ \\
\hline Acciones Propias en Cartera/ & & & $-4,974$ & $-4,974$ & $-4,974$ & $-4,974$ & $-4,974$ & $-4,974$ & & & \\
\hline |Otras Reservas de Capital/ & 1,399 & 1,399 & 1,553 & 1,553 & 1,553 & 1,553 & 1,553 & 1,553 & $1.1 \%$ & $0.8 \%$ & $0.9 \%$ \\
\hline |Resultados Acumulados/ & 47,425 & 50,647 & 49,294 & 50,420 & 51,596 & 52,823 & 54,102 & 55,435 & $36.1 \%$ & $28.6 \%$ & $28.2 \%$ \\
\hline |Otras Reservas de Patrimonio/ & 0 & 34,625 & 34,625 & 34,625 & 34,625 & 34,625 & 34,625 & 34,625 & $0.0 \%$ & $19.6 \%$ & $19.8 \%$ \\
\hline |Total Patrimonio/ & 84,056 & 121,903 & 115,979 & 118,195 & 120,494 & 122,878 & 125,349 & 127,912 & $64.0 \%$ & $68.9 \%$ & $66.4 \%$ \\
\hline TOTAL PASIVOS Y PATRIMONIO/ & 131,416 & 176,999 & 174,683 & 177,238 & 179,886 & 182,631 & 185,474 & 188,419 & $100.0 \%$ & $100.0 \%$ & $100.0 \%$ \\
\hline Fuente : BVL & 0 & 0 & 0 & 0 & 0 & 0 & 0 & 1 & & & \\
\hline
\end{tabular}

Fuente: Supertintendecia de Mercado de Valores. (s.f.a)

Elaboración propia 


\section{Anexo 2: Proyección del Estado de Resultados periodo 2018-}

\section{2}

\begin{tabular}{|c|c|c|c|c|c|c|c|c|c|c|c|c|}
\hline \multicolumn{7}{|c|}{$\begin{array}{l}\text { Estado Financiero Anual Individual del Año } 2016 \text { (En miles de nuevos soles) } \\
\text { MANUFACTURA DE METALES Y ALUMINIO "RECORD" S.A. }\end{array}$} & \multirow[b]{2}{*}{$2021 \mathrm{P}$} & \multirow[b]{2}{*}{$2022 \mathrm{P}$} & \multicolumn{3}{|c|}{ ANALISIS VERTICAL } & \multirow[t]{2}{*}{ PROMEDIO } \\
\hline ESTADO DE RESULTADOS & 2015 & 2016 & 2017 & $2018 \mathrm{P}$ & $2019 \mathrm{P}$ & $2020 \mathrm{P}$ & & & 2015 & 2016 & 2017 & \\
\hline Ingresos de Actividades Ordinarias/ & 69,104 & 80,222 & 75,723 & 78,048 & 80,445 & 82,915 & 85,461 & 88,085 & $100.0 \%$ & $100.0 \%$ & $100.0 \%$ & $100.0 \%$ \\
\hline Costo de Ventas/ & $-41,966$ & $-49,138$ & $-46,782$ & $-48,012$ & $-49,487$ & $-51,006$ & $-52,572$ & $-54,187$ & $-60.7 \%$ & $-61.3 \%$ & $-61.8 \%$ & $-61.5 \%$ \\
\hline Ganancia (Pérdida) Bruta/ & 27,138 & 31,084 & $28,941^{\prime}$ & 30,036 & 30,958 & 31,909 & $32,888^{\prime}$ & 33,898 & $39.3 \%$ & $38.7 \%$ & $38.2 \%$ & $38.5 \%$ \\
\hline Gastos de Ventas y Distribución/ & $-17,982$ & $-18,917$ & $-19,521$ & $-19,262$ & $-19,854$ & $-20,464$ & $-21,092$ & $-21,740$ & $-26.0 \%$ & $-23.6 \%$ & $-25.8 \%$ & $-24.7 \%$ \\
\hline Gastos de Administración/ & $-8,053$ & $-8,763$ & $-7,972$ & $-8,371$ & $-8,628$ & $-8,893$ & $-9,166$ & $-9,448$ & $-11.7 \%$ & $-10.9 \%$ & $-10.5 \%$ & $-10.7 \%$ \\
\hline Otros Ingresos Operativos/ & 498 & 149 & 114 & 131 & 135 & 139 & 144 & 148 & $0.7 \%$ & $0.2 \%$ & $0.2 \%$ & $0.2 \%$ \\
\hline Otros Gastos Operativos/ & -7 & -29 & 0 & -14 & -15 & -15 & -15 & -16 & $0.0 \%$ & $0.0 \%$ & $0.0 \%$ & $0.0 \%$ \\
\hline Ganancia (Pérdida) Operativa/ & 1,594 & 3,524 & $1,562^{\prime}$ & $2,519^{\prime}$ & $2,597^{\prime}$ & $2,676^{\prime}$ & $2,759^{\prime}$ & 2,843 & $2.3 \%$ & $4.4 \%$ & $2.1 \%$ & $3.2 \%$ \\
\hline Ingresos Financieros/ & 224 & 197 & 168 & 182 & 188 & 194 & 200 & 206 & $0.3 \%$ & $0.2 \%$ & $0.2 \%$ & $0.2 \%$ \\
\hline Gastos Financieros/ & -461 & -864 & $-746^{\prime}$ & -748 & $-750^{\prime}$ & -752 & -754 & -757 & $-0.7 \%$ & $-1.1 \%$ & $-1.0 \%$ & $-1.0 \%$ \\
\hline Diferencias de Cambio Neto/ & -490 & -342 & -176 & -356 & -367 & -378 & -390 & -402 & $-0.7 \%$ & $-0.4 \%$ & $-0.2 \%$ & $-0.5 \%$ \\
\hline Ganancia (Pérdida) antes de Impuesto & 867 & 2,515 & 808 & 1,598 & 1,668 & 1,740 & 1,814 & 1,891 & $1.3 \%$ & $3.1 \%$ & $1.1 \%$ & $2.05 \%$ \\
\hline Ingreso (Gasto) por Impuesto/ & -864 & -973 & -559 & -471 & -492 & -513 & -535 & -558 & $-1.3 \%$ & $-1.2 \%$ & $-0.7 \%$ & $-0.6 \%$ \\
\hline Ganancia (Pérdida) Neta del Ejercicio/ & 3 & 1,542 & 249 & 1,126 & 1,176 & 1,227 & 1,279 & 1,333 & $0.0 \%$ & $1.9 \%$ & $0.3 \%$ & $144 \%$ \\
\hline
\end{tabular}

Fuente: Supertintendecia de Mercado de Valores. (s.f.b)

Elaboración propia 


\section{Anexo 3: Proyección del Estado de Cambios en el Patrimonio Neto periodo 2018-2022}

\begin{tabular}{|c|c|c|c|c|c|c|c|}
\hline \multicolumn{8}{|c|}{$\begin{array}{l}\text { Manufactura RECORD CAMBIO PATRIMONIAL } \\
\text { RECONCILIACION DEL PATRIMONIO (en miles de soles) }\end{array}$} \\
\hline CONCEPTOSI FECHAS & 2016 & 2017 & 2018 P & $2019 P$ & $2020 P$ & $2021 \mathrm{P}$ & $2022 \mathrm{P}$ \\
\hline Patrimonio Neto Inicial: & 84,056 & 121,903 & 115,979 & 118,195 & 120,494 & 122,878 & 125,349 \\
\hline Utilidad/(Pérdida) Neta & 1,542 & 249 & 1,126 & 1,176 & 1,227 & 1,279 & 1,333 \\
\hline \multicolumn{8}{|l|}{ Acciones de inversion } \\
\hline \multicolumn{8}{|l|}{ Ajuste Patrimonial } \\
\hline Aportes de Capital & & & 1,089 & 1,123 & 1,157 & 1,193 & 1,230 \\
\hline Revaluación de inmuebles y equipo & 49,113 & & & & & & \\
\hline Dividendos/Utilidades entregadas & & $(1,388)$ & & & & & \\
\hline \multicolumn{8}{|l|}{ Ganancias por instrumentos derivados financieros } \\
\hline Compra de acciones de inversion & & $(4,725)$ & & & & & \\
\hline Impuesto a la Renta Diferido & $(12,801)$ & & & & & & \\
\hline \multicolumn{8}{|l|}{ Otras Deducciones (otro resultado integral) } \\
\hline Ajustes & (7) & (60) & & & & 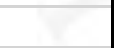 & \\
\hline Patrimonio Neto Final: & 121,903 & 115,979 & 118,195 & 120,494 & 122,878 & 125,349 & 127,912 \\
\hline Cambio Neto Patrimonial: & 37,847 & $(5,924)$ & 2,216 & 2,299 & 2,384 & 2,472 & 2,563 \\
\hline \multirow[t]{2}{*}{ VERIFICACION CUADRE DE RECONCILIACION } & 37,847 & $(5,924)$ & 2,216 & 2,299 & 2,384 & 2,472 & 2,563 \\
\hline & & & - & - & - & - & - \\
\hline
\end{tabular}

Fuente: Supertintendecia de Mercado de Valores. (s.f.a)

Elaboración propia 


\section{Anexo 4: Proyección del Estado de Flujos de Efectivo periodo 2018-2022}

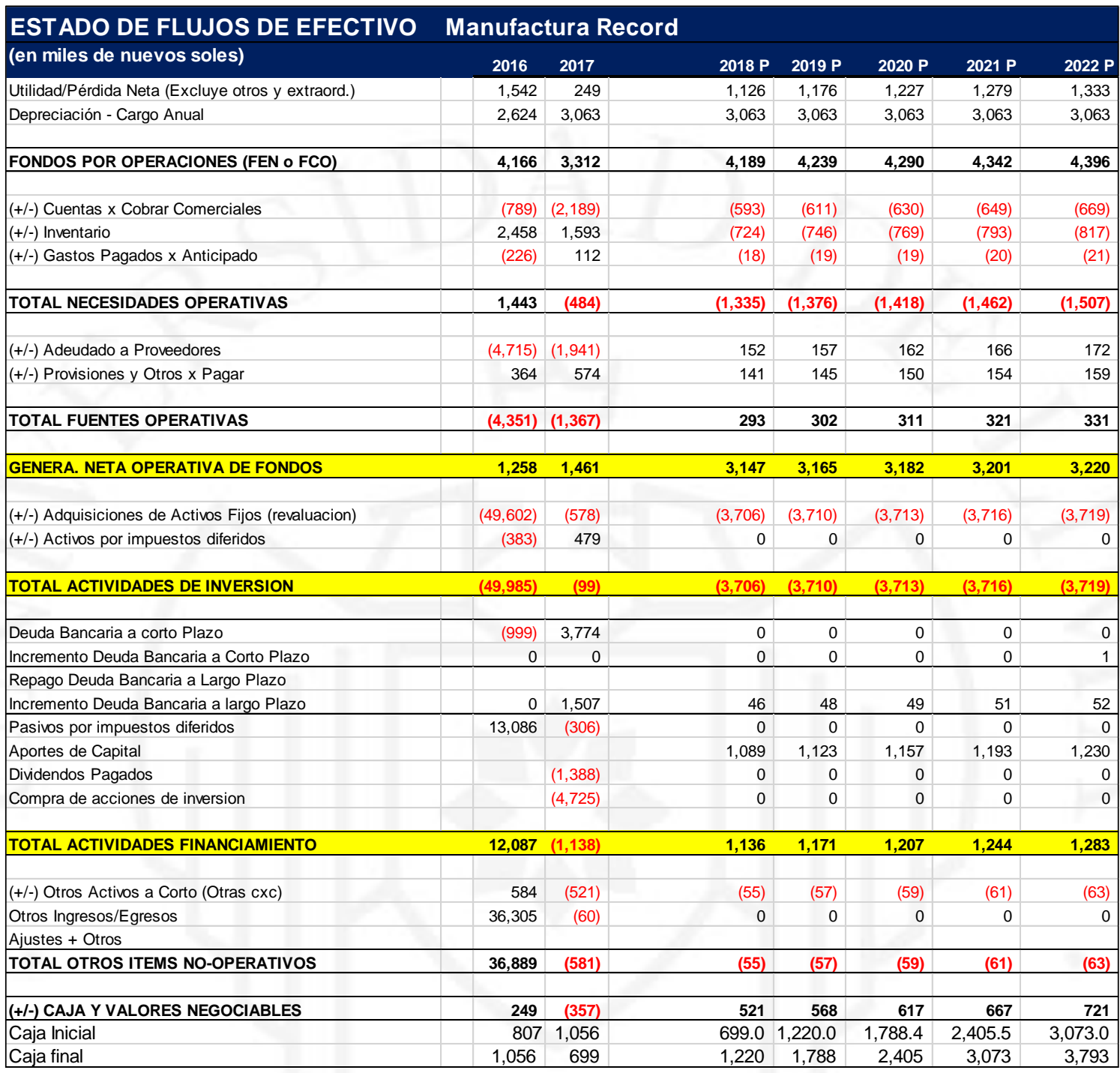

Fuente: Supertintendecia de Mercado de Valores. (s.f.b)

Elaboración propia 


\section{Anexo 5: Análisis de Ratios}

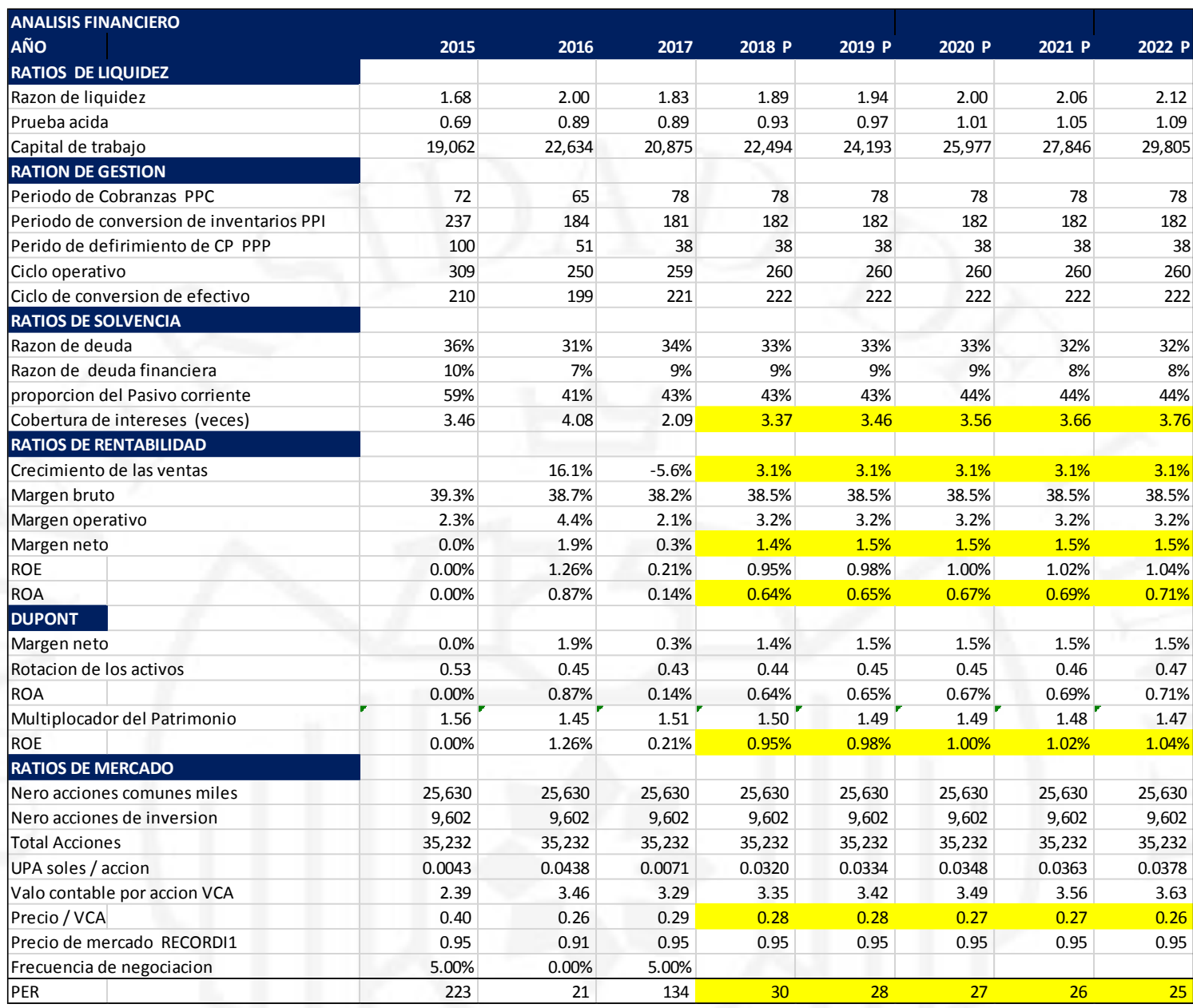

Fuente: Supertintendecia de Mercado de Valores. (s.f.b)

Elaboración propia 